\title{
Reduction of scale deposited in heat exchange equipment
}

\author{
V.A. Golovin, \\ A.N. Frumkin Institute of Physical Chemistry and Electrochemistry, Russian Academy \\ of Sciences, Leninsky pr. 31, 119071 Moscow, Russian Federation \\ *E-mail:golovin@rocor.ru
}

\begin{abstract}
This review is devoted to a range of issues related to reducing scale formation of heat exchange surfaces. The mechanisms of formation of scale deposits, the influence of structural materials used in equipment, as well as technological parameters of heat exchangers on the formation of deposits are considered. The analysis of the relationship between corrosion lesions and scale formation, mechanical, physical and chemical methods for removing and reducing the rate of scale formation, theoretical issues and experience in the use of phosphonate scale inhibitors. Considerable attention is paid to new methods of surface treatment of heat transfer surfaces, including the development of new polymer anticorrosive and anti-chip coatings and experience in their use. The potential effectiveness and prospects of solutions for the use of superhydrophobic additives and microcapsulated inhibitors are considered. Literature data show that the introduction of effective, environmentally and cost-effective methods aimed at preventing scale formation and self-cleaning will allow maintaining high performance of heat exchange equipment and avoiding unforeseen equipment repair costs associated with the development of corrosion processes on the internal surfaces of heat exchange equipment. One of the most efficient and environmentally friendly methods can be to apply anti-scaling or selfcleaning coatings on the heat exchange surfaces, which also makes it possible to simplify the cleaning of heat exchangers and preserve the characteristics of heat exchange.
\end{abstract}

Keywords: scale deposits, corrosion, inhibition, heat exchangers, polymer coatings.

Received: January 25, 2021. Published: March 31, 2021

doi: $\underline{10.17675 / 2305-6894-2021-10-2-1}$

\section{Introduction}

Despite the significant advances in water treatment, scaling and corrosion of the inner surfaces of heat exchange equipment remain a problem considerable concern in the heat and power production.

A typical situation involves the formation of a scale layer consisting of corrosion products of the metals a water cooling circuit is made of (circulation pipelines, water boxes, and heat exchange tubes) and scale deposits from water (suspended solids or dissolved salts). At the initial stage, it results in an increase in fuel consumption, reduction of reliability, efficiency, and performance of heat exchange equipment and pipelines. For example, a study on the samples of a heat exchange tube material with a $160 \mu \mathrm{m}$ thick scale layer cut from a 
condenser of a foreign nuclear power plant (NPP) demonstrated a decrease in the specific heat flux through the tube wall with scale deposits by $27 \%$.

At a neglected stage, the scale deposits can shut down the system completely, accelerate corrosion, lead local overheating, burnout, and breakage of boilers and pipes, which in turn can lead to disastrous consequences for the environment and ecological problems [1-3].

The number of pipes in a heat exchanger, for example, in the main steam condenser of an NPP turbine, can be very large and reach 100 thousand or more. Repair and refurbishment of such devices is a complicated technical problem. From 2 to $5 \%$ of the total number of heat exchanger pipes in steam condensers are currently inoperative due to corrosion and erosion damage. Analysis of corrosion state carried out at several thermal power plants (TPP) and NPPs [4] showed that another $30 \%$ of all pipes could be damaged in the nearest future by through corrosion pits. Hence, these pipes would need to be closed, which would result in an acceptable decrease in the efficiency of heat exchange equipment.

A successful solution to the problem of scale deposition to ensure a clean surface of water utilization systems, save fuel and energy resources, and prevent possible catastrophic consequences associated with damage to human life and health is a vital challenge for modern production [5].

\section{Formation of scale deposits in heat exchange equipment}

There are three forms of scale deposition in heat exchange equipment:

The primary scale is formed directly on the heating surfaces on the most heated and heat-stressed surface areas.

The secondary scale is formed from coarse particles suspended in water bulk (sludge) or entrained into the heat exchanger from the feed water system, which subsequently precipitate and adhere to the metal surface. Usually, secondary scaling occurs at small water movement rates and small heat liberation rate.

Metal corrosion products form either the primary scale deposit composed of iron or copper oxides or are included in the secondary scale.

There is no clear boundary between these kinds of deposits because, under certain conditions, scale can be transformed into sludge, and vice versa, sludge into scale.

The rate of scale formation (fouling) and the scale properties mainly depend on the composition of the water used in the heating equipment [6-9].

As a rule, power facilities are fed by natural water, including surface water (ponds, lakes, rivers, etc.) and subsurface water (artesian wells). These waters are parts of a complex dynamic eco-geochemical system containing mineral and organic compounds in molecular, truly dissolved, colloid, and suspended state, as well as gases.

It is evident that the chemical composition of scale deposits on heat power equipment is an objective indicator of the composition and quality of the natural and treated water used in operation. 
Calcium carbonate is the main component of the low-temperature scale deposits (primary scales) formed on the heating surface of a water heating system. Scale deposits can be quite considerable in the heating units of hot water supply (where water is heated up to $70^{\circ} \mathrm{C}$ ) due to utilization of natural water without preliminary treatment that is limited by relevant regulations. In addition to the carbonate scale, the scale deposits in heat exchange equipment can contain iron oxides, calcium sulfate, silicates, phosphates, and others, depending on the chemical composition of the source water and the specific operating conditions [10-13].

The presence of a significant amount of magnesium in natural water is among the factors that favor a good operating condition of a heat exchanger. At a $\mathrm{Mg}^{2+} / \mathrm{Ca}^{2+}$ ratio of $1: 2$ and $\mathrm{pH}>8.0$, aragonite is formed, which makes the structure of deposits less coherent than calcite. These deposits easily fall down from the pipes to the boiler's bottom and are removed by periodic and well-timed boiler bottom blowdown. As practice shows, daily laboratory monitoring of the chemical composition of natural, treated, and boiler feed water makes it possible to keep the equipment in good operating condition even by the simplest water treatment methods.

The content of gases, various impurities, and dissolved compounds in waters should be reduced by some preliminary water treatment methods.

This approach is supported by the fact that during the operation of heating equipment accompanied by changes in pressure and temperature, the residual amounts of the above compounds initiate corrosion processes, affect the metal surface properties, and give rise to corrosion scale deposits with various chemical composition and structure on the internal surface of heat exchangers.

\subsection{Mechanism of scale formation from dissolved compounds}

Scale deposition on a heating surface results from processes in the heated environment, associated with the formation of poorly soluble compounds due to concentrating of salts upon repeated evaporation of feed water, and a decrease in solubility of some compounds caused by an increase in temperature [14].

As the salt concentration in water increases due to its evaporation, crystallization centers of compounds whose solutions are closest to saturation appear in the solution. The subsequent crystallization process is accompanied by the growth of crystals and results in the release of a solid phase, either directly on the heating surfaces with the formation of scale, or in the water bulk in the form of tiny crystals which then grow and compose sludges. Thus, the fouling process is based on the separation of a solid phase from a supersaturated aqueous solution of scale-forming salts. Both the mechanism and intensity of salt deposition are determined by the content of these salts in natural and treated waters.

The composition and structure of scale deposits in heat exchangers depend on the composition of natural water, water chemistry conditions, surface heat load, and water circulation intensity [15-17]. 
Scale deposits are classified by the chemical composition, based on the nature of the predominant constituent:

- deposits of alkaline-earth metals containing $\mathrm{CaCO}_{3}, \mathrm{CaSO}_{4}, \mathrm{CaSiO}_{3}, \mathrm{Ca}_{3}\left(\mathrm{PO}_{4}\right)_{2}$, $\mathrm{MgO} \cdot \mathrm{Mg}(\mathrm{OH})_{2}, \mathrm{Mg}_{3}\left(\mathrm{PO}_{4}\right)_{2}$, and $5 \mathrm{CaO} \cdot 5 \mathrm{SiO}_{2} \cdot \mathrm{H}_{2} \mathrm{O}$. Depending on the predominant anion, they are divided into carbonate, sulfate, phosphate, and silicate deposits;

- iron oxide (containing 70-90\% of iron oxide - usually a mixture of magnetite $\mathrm{Fe}_{3} \mathrm{O}_{4}$ and hematite $\mathrm{Fe}_{2} \mathrm{O}_{3}$ with related impurities, and iron phosphates $\left[\mathrm{NaFePO}_{4}\right.$, $\left.\mathrm{Fe}_{3}\left(\mathrm{PO}_{4}\right)_{2}\right]$

- copper - 30 or more percent of copper as the metal and oxides with admixtures of iron oxides, calcium and magnesium compounds.

A small solubility product is characteristic of $\mathrm{CaCO}_{3}, \mathrm{MgCO}_{3}, \mathrm{CaSO}_{4}, \mathrm{Ca}_{3}\left(\mathrm{PO}_{4}\right)_{2}$, $\mathrm{Mg}(\mathrm{OH})_{2}$, and $\mathrm{Ca}_{5}\left(\mathrm{PO}_{4}\right)_{3} \mathrm{OH}$ (see Table 1) [18].

Table 1. The solubility products [SP] of some inorganic compounds under normal conditions $\left(T=25^{\circ} \mathrm{C}\right.$, $P=1 \mathrm{~atm})$.

\begin{tabular}{ccccccc}
\hline Compound & $\mathrm{CaCO}_{3}$ & $\mathrm{MgCO}_{3}$ & $\mathrm{Mg}(\mathrm{OH})_{2}$ & $\mathrm{Ca}_{3}\left(\mathrm{PO}_{4}\right)_{2}$ & $\mathrm{CaSO}_{4}$ & $\mathrm{Ca}_{5}\left(\mathrm{PO}_{4}\right)_{3} \mathrm{OH}$ \\
\hline $\begin{array}{c}\text { Solubility } \\
\text { product }[\mathrm{SP}]\end{array}$ & $3.8 \cdot 10^{-9}$ & $2.1 \cdot 10^{-5}$ & $6.0 \cdot 10^{-10}$ & $2.0 \cdot 10^{-29}$ & $2.5 \cdot 10^{-5}$ & $1.6 \cdot 10^{-58}$ \\
\hline
\end{tabular}

The formation of carbonate is determined by the solution $\mathrm{pH}$ :

$$
\mathrm{CO}_{2}+\mathrm{H}_{2} \mathrm{O} \leftrightarrow \mathrm{H}_{2} \mathrm{CO}_{3} \leftrightarrow \mathrm{H}^{+}+\mathrm{HCO}_{3}^{-} \leftrightarrow 2 \mathrm{H}^{+}+\mathrm{CO}_{3}^{2-}
$$

At $\mathrm{pH}<4.0$, carbonic acid exists entirely as carbon dioxide $\mathrm{CO}_{2}$.

At $\mathrm{pH}=8.4, \mathrm{HCO}_{3}^{-}$ions are predominant;

At $\mathrm{pH}>10.5$, only $\mathrm{CO}_{3}^{2-}$ ions are present.

The main reason for carbonate buildup in a heat supply network lies in the thermal degradation of bicarbonates that can exist in water only if the latter contains free dissolved carbon dioxide whose amount depends both on the pressure of carbon dioxide above the water surface and on the water temperature.

An increase in the water temperature results in a decrease in the amount of free dissolved carbonic acid. As a result, bicarbonates decomposed with release of free carbonic acid:

$$
2 \mathrm{HCO}_{3}^{-} \leftrightarrow \mathrm{CO}_{3}^{2-}+\mathrm{H}_{2} \mathrm{CO}_{3} \leftrightarrow \mathrm{CO}_{3}^{2-}+\mathrm{CO}_{2} \uparrow+\mathrm{H}_{2} \mathrm{O}
$$

Subsequent reactions include the formation of calcium and magnesium carbonates:

$$
\begin{gathered}
\mathrm{CO}_{3}^{2-}+\mathrm{Ca}^{2+} \rightarrow \mathrm{CaCO}_{3} \downarrow \\
\mathrm{CO}_{3}^{2-}+\mathrm{Mg}^{2+} \rightarrow \mathrm{MgCO}_{3} \downarrow
\end{gathered}
$$


The saturation of the heating-system water with $\mathrm{MgCO}_{3}$ can be achieved by increasing the $\mathrm{Mg}^{2+}$ concentration by several orders of magnitude compared to that for $\mathrm{Ca}^{2+}$ at the same concentration of $\mathrm{CO}_{3}^{2-}$, since $\mathrm{SP}\left[\mathrm{MgCO}_{3}\right]=2.1 \cdot 10^{-5}, \mathrm{SP}\left(\mathrm{CaCO}_{3}\right)=3.8 \cdot 10^{-9}$. The solubility of magnesium carbonate exceeds that of calcium carbonate almost fourfold. Therefore, upon hydrolysis of $\mathrm{MgCO}_{3}$, when the $\mathrm{pH}$ reaches 10, magnesium hydroxide ions are bound by hydroxide ions to form sparingly soluble $\mathrm{Mg}(\mathrm{OH})_{2}[19,20]$.

As the temperature rises above $75^{\circ} \mathrm{C}$, carbonate ions react with water to give hydroxide ions, which bind with magnesium ions to give magnesium hydroxide. The solubility of magnesium hydroxide is four times smaller than that of calcium carbonate: $\mathrm{SP}\left[\mathrm{Mg}(\mathrm{OH})_{2}\right]=$ $6.0 \cdot 10^{-10}$ :

$$
\begin{aligned}
& \mathrm{CO}_{3}^{2-}+\mathrm{H}_{2} \mathrm{O} \leftrightarrow \mathrm{CO}_{2} \uparrow+\mathrm{OH}^{-} \\
& \mathrm{Mg}^{2+}+2 \mathrm{OH}^{-} \rightarrow \mathrm{Mg}(\mathrm{OH})_{2} \downarrow
\end{aligned}
$$

It was shown [21] that the deposition of magnesium hydroxide becomes stronger with an increase in the surface temperature and flow rate. In contrast, the deposition of calcium carbonate becomes stronger with a rise in the surface temperature and weaker with an increase in the flow rate.

The formation of sulfate scale is a consequence of a decrease in the solubility of calcium sulfate with an increase in temperature, which is typical of desalinating and heat-exchanging equipment intended for heating of seawater or highly mineralized water (thermal desalination units, evaporator systems, condensers). Sulfate scale is hardly soluble and it is very difficult to prevent its formation.

There are three kinds of sulfate scale:

- anhydrite $\mathrm{CaSO}_{4}$ (the least soluble);

- semihydrate $\mathrm{CaSO}_{4} \cdot 1 / 2 \mathrm{H}_{2} \mathrm{O}$;

- gypsum $\mathrm{CaSO}_{4} \cdot 2 \mathrm{H}_{2} \mathrm{O}$.

The general process of calcium sulfate crystallization on heat exchange surfaces depends on the solution supersaturation, surface temperature, boiling process, flow rate, and ion diffusion, as well as on the processes that occur in scale [22-25]. In such a system, $\mathrm{CaSO}_{4} \cdot 2 \mathrm{H}_{2} \mathrm{O}$ is the most stable form at temperatures up to $63^{\circ} \mathrm{C}$, all three modifications of calcium sulfate exist within the temperature range from 63 to $107^{\circ} \mathrm{C}$, and anhydrite and semihydrate are stable within the range from 107 to $200^{\circ} \mathrm{C}$. Only anhydrite can exist at temperatures above $200^{\circ} \mathrm{C}$ [26].

Silicate scales have diverse mineralogical compositions $\left(\mathrm{CaSiO}_{3}, 5 \mathrm{CaO} \cdot 5 \mathrm{SiO}_{2} \cdot \mathrm{H}_{2} \mathrm{O}\right.$, $3 \mathrm{Mg} \cdot 2 \mathrm{SiO}_{2} \cdot \mathrm{H}_{2} \mathrm{O}, \mathrm{Na}_{2} \mathrm{O} \cdot \mathrm{Fe}_{2} \mathrm{O}_{3} \cdot \mathrm{SiO}_{2}$, etc.). They form dense, porous, or lumpy deposits. This variety can be attributed to the ability of silicic acid to form scales with not only calcium and magnesium cations but also with aluminum, iron, sodium, etc. [27]. Silicon dioxide reacts with calcium and magnesium salts to give silicates with very low thermal conductivity. Silica present in water in colloidal state as $\mathrm{SiO}_{2} \cdot \mathrm{H}_{2} \mathrm{O}$ or polysilicic acid $x \mathrm{SiO}_{2} \cdot y \mathrm{H}_{2} \mathrm{O}$ is transported 
and reprecipitates, or else reacts and then precipitates as scale on the heat exchange surface [28].

It was shown that silica could be evaporated with steam in concentrations sufficient for deposition on the surfaces of heating equipment, and its solubility directly depends on the steam pressure, density, and temperature [29].

The formation of iron oxide scale on the internal surfaces of heating equipment depends on the $\mathrm{pH}$ of water and the content of corrosion activators, such as carbon dioxide, oxygen, sulfates, and chlorides, as well as on iron bacteria. Iron oxide scale composed of magnetite $\mathrm{Fe}_{3} \mathrm{O}_{4}$, hematite $\mathrm{Fe}_{2} \mathrm{O}_{3}$, wustite $\mathrm{FeO}$, and goethite $\mathrm{FeO}(\mathrm{OH})$ may form dense layers with a smooth surface, rough, bumpy, or porous, and sometimes rather loose. Iron oxide scale may be black, dark-gray, gray-brown, deep-brown, umber, or ochre-green. The appearance of iron oxide scale on the internal surfaces of heating equipment is a result of both metal corrosion processes and deposition of those iron oxides that were present in boiler water [30, $31]$.

Failure to maintain the parameters of boiler water phosphating gives rise to iron phosphate scale deposition in drum boilers. It starts at $250^{\circ} \mathrm{C}$ evolves with an increase in temperature and an increase in the excess of phosphates in boiler water [32].

Copper scale was reported in heat supply systems at various pressures where copper compounds enter feed water. Copper scale is formed from the corrosion products of brass (heater tubes) and other copper alloys (condensate pipelines) entering the water with an increase in the $\mathrm{pH}$ above 9.0 due to copper dissolution in the presence of ammonia and oxygen in water. The formation of copper scale is caused by the electrochemical reduction of copper from its compounds on a metal surface, resulting from a local potential difference between the separate sections of the heating surface.

Effect of structural materials, thermal and hydraulic parameters on the formation of deposits in heating systems

It has been found that bubbles with round bases that are formed in water and contact the walls of heat transfer surfaces promote the precipitation and crystallization of particles due to an increase in supersaturation with the bubble growth and evaporation of liquid from it. As a result, a microscopic layer of solids is formed on the surface. Due to the continuous change of bubbles, the entire heat exchange surface is gradually covered with scale [33].

Calcium carbonate that has a number of crystalline modifications is the most common compound formed on heat exchange surfaces. Supersaturation in water is the driving force for its crystallization.

There is abundant evidence that any energy heterogeneity can serve as a nucleation center: a free radical, an electrically charged particle, crystalline defects, as well as the crystal structure itself that has free surface energy. 
The surface of a heat exchanging material can serve as a matrix for the formation of a salt crystal if the configurations of their unit cells (syngony) coincide and the parameters of their crystal lattices do not differ by more than $20 \%$ [34].

The absolute value of crystallographic mismatch (D) is considered as a criterion for the activity of a heat exchange surface to possible deposits:

$$
D=\left|a_{\text {surf }}-a_{\text {cr }}\right| / a_{\text {cr }}=\left|a_{\text {surf }} / a_{\text {cr }}-1\right| .
$$

Here, $a_{\text {surf }}$ is a crystalline lattice parameter of a material from which the heat exchange surface is composed; $a_{\mathrm{cr}}$ is the crystalline lattice parameter of the crystallizing compound $\left[\mathrm{CaCO}_{3}, \mathrm{FeCO}_{3}, \mathrm{Fe}(\mathrm{OH})_{2}, \mathrm{Fe}_{2} \mathrm{O}_{3}\right]$.

The smaller the crystallographic mismatch, i.e., the closer the parameters of the substrate and scale, the more intense the surface will initiate the crystal nucleus formation of the crystallizing compound and the smaller the supersaturation at which this occurs. Based on the calculations of the values of crystallographic mismatch given in Table 2, it has been shown that the formation of an intermediate layer composed of iron oxides or carbonates is a prerequisite for the presence of calcium carbonate on an iron surface since the indicators of crystallographic mismatch are smaller than 0.2 .

Table 2. Parameters of crystalline lattices and mutual crystallographic mismatch.

\begin{tabular}{cccc}
\hline Chemical formula & $\begin{array}{c}\text { Crystallographic } \\
\text { modification }\end{array}$ & $\begin{array}{c}\text { Crystal lattice } \\
\text { parameter } \boldsymbol{a}, \boldsymbol{\AA}\end{array}$ & $\begin{array}{c}\text { Crystallographic } \\
\text { mismatch }\end{array}$ \\
\hline $\mathrm{CaCO}_{3}$ & calcite & 4.893 & 0.000 \\
$\alpha-\mathrm{Fe}$ & hematite & 2.866 & 0.414 \\
$\mathrm{Fe}_{2} \mathrm{O}_{3}$ & & 5.420 & 0.108 \\
$\mathrm{Fe}(\mathrm{OH})_{2}$ & siderite & 3.240 & 0.338 \\
$\mathrm{FeCO} 3$ & aragonite & 4.627 & 0.054 \\
$\mathrm{CaCO}_{3}$ & & 5.720 & 0.000 \\
$\alpha-\mathrm{Fe}$ & hematite & 2.866 & 0.499 \\
$\mathrm{Fe} \mathrm{O}_{3}$ & & 5.420 & 0.052 \\
$\mathrm{Fe}\left(\mathrm{OH}_{2}\right.$ & siderite & 3.240 & 0.434 \\
$\mathrm{FeCO}_{3}$ & & 4.627 & 0.191 \\
\hline
\end{tabular}

As follows from calculations, calcite and aragonite do not crystallize on a chemically pure iron surface but can crystallize on corrosion products and their derivatives.

The interaction between the heat exchange surface material and water flow elements, such as dispersed particles, salt ions, corrosion products, etc., is an important factor that affects the fouling processes. 
The surface temperature parameters, the level of which determines the formation of a specific porosity, and hence, thermal conductivity, affect to a large extent the structure, morphology, and thermophysical properties of deposits. Kazi [35] has shown that an increase in the specific heat flow through a heat exchange wall by a factor of $1.5-2$ leads to a 5-6 fold increase in deposits.

The larger the layer of deposits and the smaller their heat conductivity coefficient, the more strongly the wall surfaces will warm up. The heat conductivity of deposits, which contributes significantly to the efficiency of the heat exchange processes, varies within a wide range from 0.3 to $1.2-1.6 \mathrm{~W} /(\mathrm{m} \cdot \mathrm{K})$ for low-temperature heat exchangers and to $3.0-$ $3.5 \mathrm{~W} /(\mathrm{m} \cdot \mathrm{K})$ for steam-generating units and steam boilers used in systems with pretreated water. Scale deposits reduce the heat conductivity, and the more porous they are, the smaller thermal conductivity they possess.

The effect of scale thickness on the surface temperature was studied in [36]. It was shown that when the thickness of the scale layer varied from 0.1 to $0.3 \mathrm{~mm}$, the temperature reached $500^{\circ} \mathrm{C}$ on the most heat-stressed regions of wall tubes and depended on the thermal conductivity of scale that ranged within $0.1-7.0 \mathrm{~W} / \mathrm{m} \cdot{ }^{\circ} \mathrm{C}$. In this case, silicate deposits are most dangerous since their thermal conductivity is 300 times smaller than that of cast iron and steel.

The scaling intensity depends on the water flow rate, with the growth of which the thickness of a wall layer decreases. Also, scale deposition depends on the processes of delivery of impurities to a surface and removal of particles from it [37]. The higher the flow rate, the higher the frequency of hydrodynamic pulsation that prevents the attachment of a crystal to the surface. A microcrystal detached by the flow continues to grow in the liquid bulk. At flow rates in tubes ranging from 0.5 to $1.5 \mathrm{~m} / \mathrm{s}$, only particles with sizes above 10-20 $\mu \mathrm{m}$ are washed out, whereas as a rule, dispersed particles with smaller sizes are attached to the heat exchange surface.

There are three ranges of flow rate that affect the scaling intensity:

- at flow rates below $0.3 \mathrm{~m} / \mathrm{s}$, the average integral scaling intensity, which depends on the delivery of impurities to the walls via diffusion, varies insignificantly;

- when the flow rate is within the range from 0.3 to $1.5 \mathrm{~m} / \mathrm{s}$, it has practically no effect;

- at flow rates exceeding $1.5 \mathrm{~m} / \mathrm{s}$, the growth rate changes by a factor of $1.5-6$ and depends on the flow turbulence.

A study on the structure and thermophysical properties of scale deposits on heating surfaces made of St 20 steel and $1 \mathrm{Kh} 18 \mathrm{~N} 12 \mathrm{E}$ stainless steel revealed that the scaling intensity depends on the flow mode: it occurs unsystematically in a turbulent flow, whereas in a laminar flow, in the form of longitudinal rows. The amount of deposits on stainless steel surface was 8-10 times smaller, depending mainly on the surface irregularities and roughness. 
It should be noted that the thermal conductivity of stainless steel $(17 \mathrm{~W} / \mathrm{m} \cdot \mathrm{K})$ is several times smaller than that of carbon steel $(51 \mathrm{~W} / \mathrm{m} \cdot \mathrm{K})$.

It is reasonable to expect that the stability of a colloidal system would depend on the value and sign of the electrode potential of the heat exchange surface. The most suitable materials for heat exchange equipment are brasses and stainless steel whose surface potentials are from -0.25 to $0.15 \mathrm{~V}$.

The electrode potential or surface energy can be changed by applying polymer films and coatings to metal surfaces.

Studies on the effect of surface energy on scaling have shown that scale deposition can be mitigated significantly by minimizing polar areas on the heat exchange surface, i.e., due to a decrease in surface energy from 52 to $10 \mathrm{~mJ} / \mathrm{m}^{2}$ resulting from the application of dielectric coatings that increase an energy barrier for crystal nucleation.

It was found that no scale crystallization centers formed on steel surfaces coated with fluoroplastics with an amorphous structure and an electrode potential two times smaller than that of the substrate. When the coating was damaged, cracks served as supersaturation zones where crystal nucleation and coagulation occurred.

Thus, it can be argued that polymers are promising materials for anti-scale protection of heat exchange equipment.

As noted above, corrosion products are one of the constituents of deposits on heat exchange surfaces.

\subsection{Effect of corrosion on scaling}

The heat exchange equipment for power engineering is currently made of the following materials: copper-nickel alloys (MNG 5-1), brass L68, stainless steel, and titanium alloys.

The conditions for development of corrosion processes in heat exchange equipment used at power stations differ significantly, depending on the cooling water composition and temperature. For example, nuclear power plants mainly use natural fresh water from cooling ponds, rivers, or seawater. Thermal power plants typically utilize recycling water supply with cooling towers, allowing the use of specific additives, for example, anti-scale agents. The salt content in cooling water of closed reservoirs can range from 100 to $3000 \mathrm{mg} / \mathrm{l}$ and may vary significantly depending on the season and conditions of replenishment of cooling ponds.

The most important origins of the differences in the operating conditions of heat exchanger tubes include the variety and wide range of concentrations of natural and synthetic reagents contained in cooling water. It should also be taken into account that the temperature of water supplied for cooling can also vary from 3 to $28^{\circ} \mathrm{C}$, which in turn affects the corrosion processes.

From the standpoint of ensuring the stable operation of vapor condensers and heat exchangers, the greatest danger lies in the violation of the tightness of heat exchanger pipes, 
which leads to the inleak of mineralized cooling water into the steam space, its contamination, and vacuum reduction.

As follows from the experience in the repair and inspection of heat exchanger pipes in electric power condensers, the main cause of the leakage is the development of local corrosion. The share of local corrosion damage is more than $70 \%$ of the total number of defects. Despite the difference in operating conditions and materials used for heat exchange equipment, two types of corrosion damage can be distinguished:

- destruction of tubes and tube sheets around the rolling zone due to corrosive-erosive wear and bimetallic corrosion (Figure 1);

- development of sporadic corrosion pits (Figure 2) or pit clusters (Figures 3 and 4) located along the entire length of the inner tube surfaces (on the coolant side). Such pits vary widely in size and depth, up to perforation. This type of corrosion damage was revealed for tubes made of $\mathrm{Cu}-\mathrm{Ni}$ alloys, brass, and stainless steel (Figure 5), both in fresh and sea water.

An additional hazard is posed by secondary destruction processes since corrosion pits can act as stress concentration points and initiate the formation of local cracks under hydraulic shock (Figure 6). Cracking can also result from dezincification corrosion damage of brass pipes on the coolant side (Figure 7) if acid cleaning or cooling water acidifying is performed.

The main types of corrosion damage of heat exchanger pipes include:

- a corrosion ulcer with subsequent development as a crack by the stress corrosion cracking mechanism;

- an agglomeration of ulcers (pits) that are small in size and located mainly in the lower parts of heat exchanger pipes;

- cracking by the intercrystallite, transcrystallite and mixed mechanisms;

- corrosion in the form of extended shallow spots.

A crack or ulcer transformed into a crack via the stress corrosion cracking mechanism is not only the most common but also most dangerous defect in heat exchanger pipes of steam generators. According to numerous studies, the corrosion crack propagation rate is many times higher than the rate of overall or ulcer corrosion of metals. Corrosion cracking of the metal of heat exchanger pipes is primarily due to corrosive impurities such as chlorides and sulfates contained in the boiler water of steam generators. Their accumulation in the deposits formed on the surface of heat exchanger pipes in the course of heat exchange also facilitates the corrosion cracking of the metal [38, 39].

It should be noted that when water is circulated in a system, part of it evaporates in the cooling tower, from the surface of open ponds, and from the reservoirs of wastewater treatment facilities resulting in an increase in the concentration of salts and scale-forming compounds. Repeated use of water leads to the accumulation of a coarse dispersion, various 
corrosive compounds, and microorganisms. The presence of all of them causes intense scale deposition, which leads to local overheating and corrosion of condensing and refrigerating equipment. They impair the heat transfer processes and lead to weakening of the mechanical strength of the metal constituting the coil tubes and apparatus bodies.

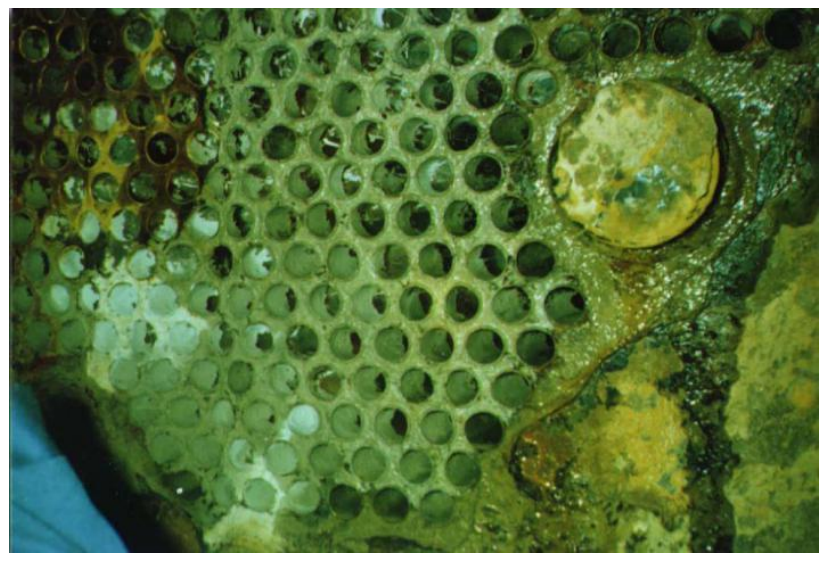

Figure 1. An example of corrosion destruction of the tube plates and entrance regions of the heat exchanger pipes at the South Ural NPP.

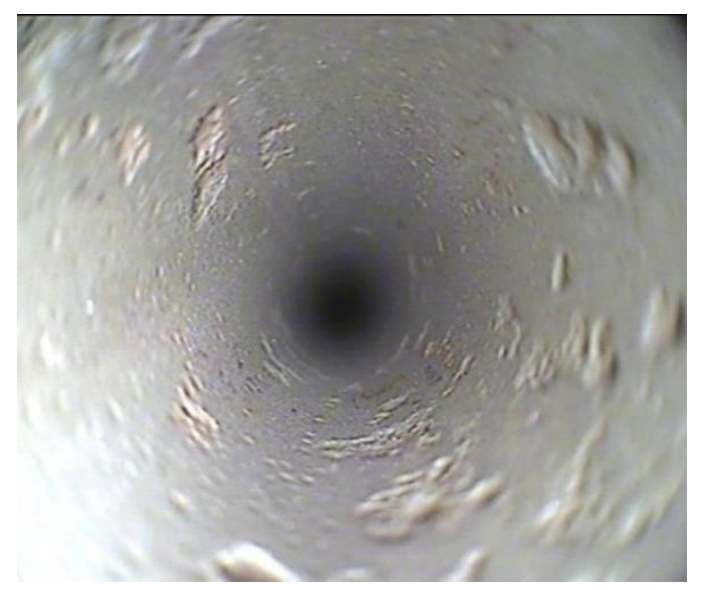

Figure 3. A snapshot of a video inspection of the inner surface of a heat exchanger tube of the condenser with multiple surface (blind) corrosion ulcers (at the Leningrad NPP).

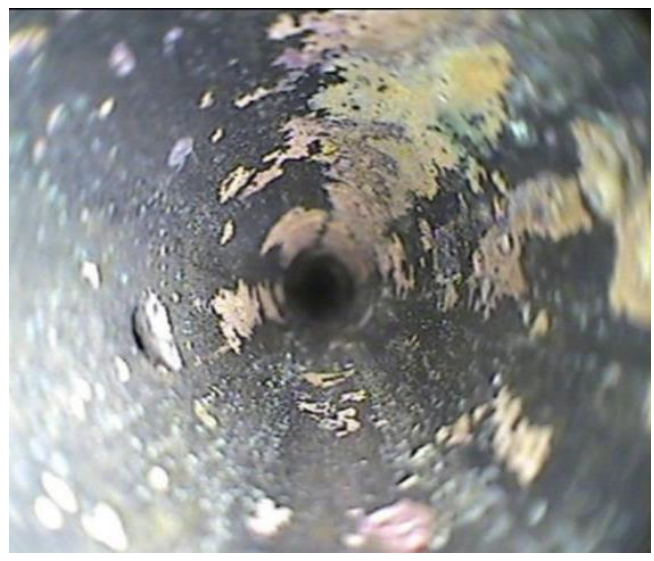

Figure 2. A snapshot from the video inspection of the inner surface of a heat exchanger tube with a single through corrosion ulcer and a scale region (at the Leningrad NPP).

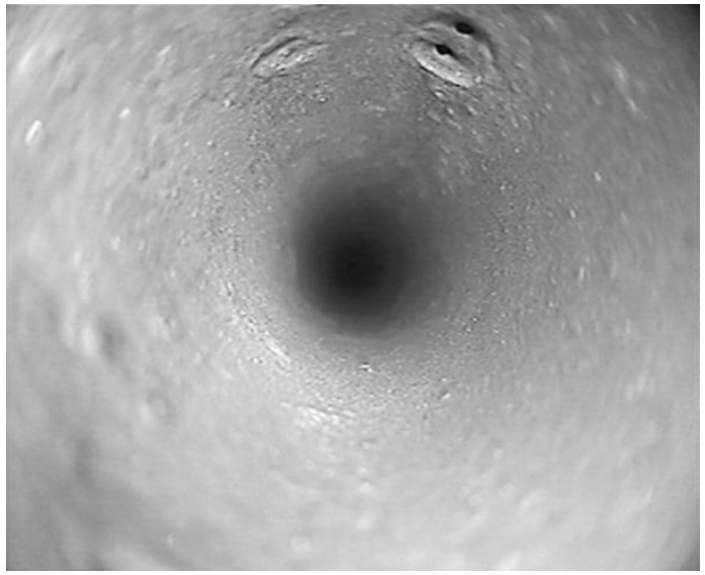

Figure 4. A snapshot of a video inspection of the inner surface of a heat exchanger tube of a condenser cleaned from deposits with a double through corrosion ulcer (at the Balakovo NPP).

Thus, the considered results of analyzing heat exchange surfaces revealed the presence of a mutual relationship between corrosion and fouling: corrosion damages, especially local ones, stimulate the scale deposition process, while the scale or deposits promote the development of local corrosion ulcers. 

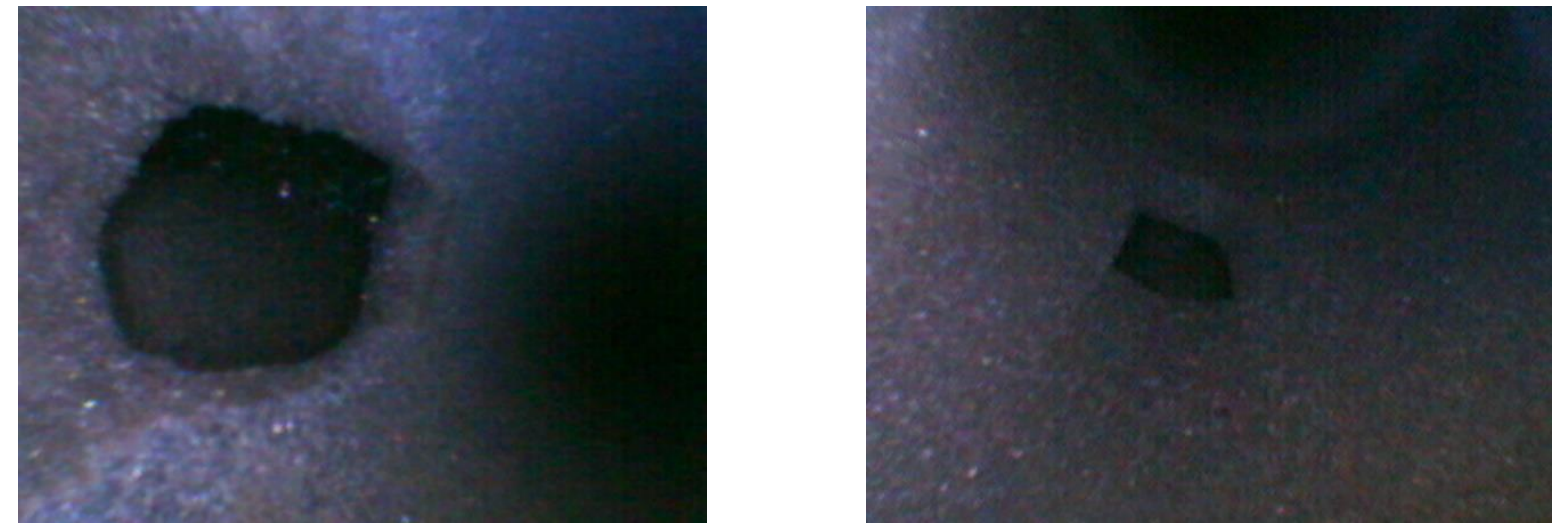

Figure 5. Corrosion ulcers in a heat exchanger tube made of Kh18N10T steel.

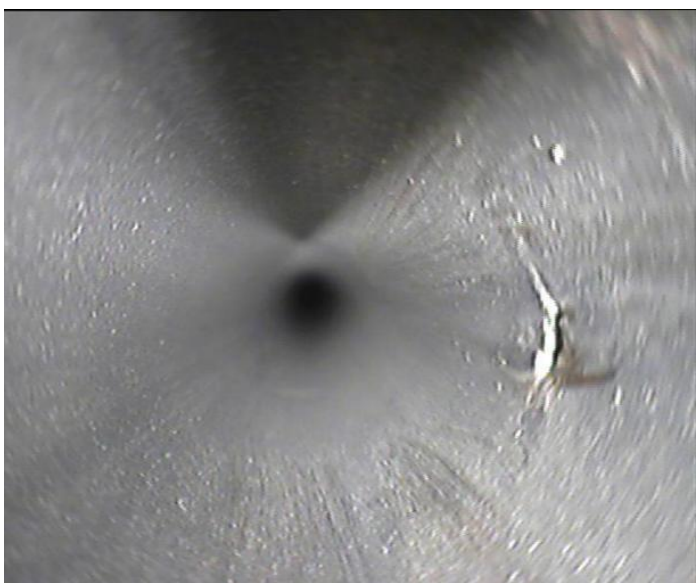

Figure 6. A snapshot of a video inspection of the inner surface of a heat exchange tube with an ulcer and a radial crack initiated by it (at the Kalinin NPP).

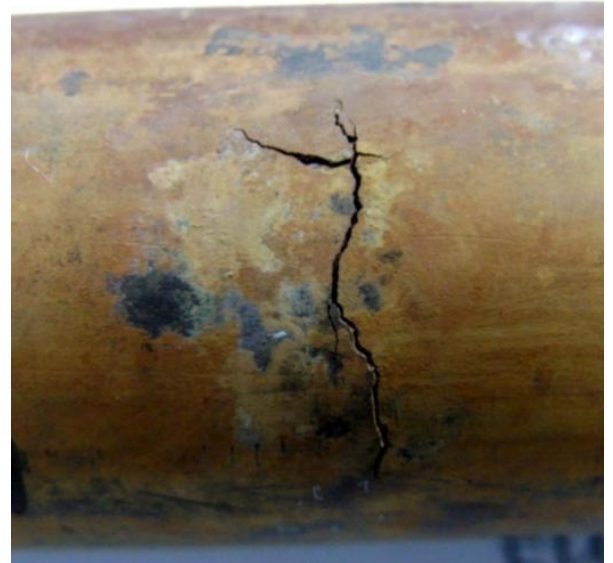

Figure 7. A photo of the outer surface of a TPP heat exchange tube subjected to continuous dezincification and cracking with a hairline crack.

\section{Methods of fouling mitigation and scale removal from the surfaces of thermal power equipment}

Periodic cleaning of a heat exchange surface is a necessary operation in maintaining heat exchange equipment, which is essential for ensuring the required heat transfer performance $[40,41]$.

The variety of composition and physicochemical properties of scale implies various ways to reduce and remove it.

A number of methods are employed to mitigate fouling processes in water desalination plants, including:

- acidification of water and application of anti-scale additives;

- incorporation of granular additives (seeds);

- contact stabilization; 
- use of specially designed evaporators with movable and self-cleaning heat exchange surfaces;

- magnetic, ultrasonic, and radiation treatment of feed water.

The choice of the cleaning technique for the interior surfaces is also determined by the type of fouling.

These methods can be tentatively divided into three groups: chemical, mechanical, and physical.

\begin{tabular}{|c|c|}
\hline Type of fouling & Cleaning technique \\
\hline \multirow[t]{8}{*}{ Chemical deposits } & - Mechanical cleaning \\
\hline & - Chemical cleaning \\
\hline & - High-pressure devices \\
\hline & - Hydrocavitational method \\
\hline & - Pulsed electrohydraulic method \\
\hline & - Ultrasonic cleaning \\
\hline & - Vibratory cleaning \\
\hline & - Cleaning with pneumatic closing plugs \\
\hline \multirow[t]{9}{*}{ Mechanical deposits } & - Mechanical cleaning \\
\hline & - High-pressure devices \\
\hline & - Hydro-pneumatic cleaning \\
\hline & - High-speed washing \\
\hline & - Hydrocavitational method \\
\hline & - Circulation reversal \\
\hline & - Pulsed electrohydraulic method \\
\hline & - Electromagnetic treatment \\
\hline & - Cleaning with pneumatic closing plugs \\
\hline \multirow[t]{11}{*}{ Biological fouling } & - Mechanical cleaning \\
\hline & - Chemical cleaning \\
\hline & - High-pressure devices \\
\hline & - Hydro-pneumatic cleaning \\
\hline & - High-speed washing \\
\hline & - Hydrocavitational method \\
\hline & - Thermal and vacuum drying \\
\hline & - Ball cleaning System \\
\hline & - Pulsed electrohydraulic method \\
\hline & - Electromagnetic treatment \\
\hline & - Cleaning with pneumatic closing plugs \\
\hline
\end{tabular}




\subsection{Mechanical methods of deposit removal}

The well-known and widely used mechanical methods for deposit removal include the use of scrapers, perforators, side cutters, and shaped hammer-stones. These methods involve mostly manual unproductive labor associated with complete or partial disassembly of the power equipment. Moreover, the environmental hazard of the resulting waste should be noted.

The most promising and well-proven method is the cleaning technique based on the use of a ball cleaning. The operational principle of these systems involves a continuous circulation of porous rubber balls through condenser tubes; the diameter of these balls is 1-2 mm larger than the inner diameter of the tubes. When the balls move through the tubes, they clean the inner surfaces by removing all deposits at early stages, thus preventing further growth. The balls differ in diameter, hardness, and operating temperature. Balls containing an abrasive that can be injected inside or applied as a surface coating were developed. Moreover, the balls can either be covered entirely with an abrasive or have an abrasive belt.

The majority of condensers at the NPPs and some condensers at TPPs are equipped with such ball-bearing cleaning systems. During a scheduled preventive maintenance, the cleaning procedure is carried out using high-pressure devices. However, the high adhesion of the scale deposits to the metal walls and their hardness sometimes prevent achieving the design characteristics of condensers. Part of the deposits still remains, and this process has a cumulative effect. The oxidized metal surface, which is additionally developed due to corrosion processes, is an ideal substrate for the scale accumulation.

The installation of a ball cleaning system is very expensive. Additional costs are associated with the periodic replacement of balls.

\subsection{Physical methods of fouling mitigation}

The use of physical methods for scale removal is a well-established cleaning practice. For example, a cavitation chamber is used for cleaning pipelines; various techniques based on electrical pulse discharge in liquids and ultrasound are employed for cleaning thermotechnical surfaces [42, 43]. Many physical and mechanical cleaning methods are also known. However, they are applicable mainly for the destruction and removal of loose deposits and are not always effective for the removal of dense and glass-like deposits.

The application of physical methods, including magnetic, ultrasonic, and highfrequency current treatments, makes it possible to avoid the formation of harmful effluents. This is important for the environment but does not entirely prevent corrosion and fouling of the surface of thermotechnical equipment.

\subsubsection{Magnetic treatment}

The effect of magnetic treatment involves the prevention of scale deposition by removal of insoluble hardness salts such as $\mathrm{Mg}(\mathrm{OH})_{2}$ and $\mathrm{CaCO}_{3}$ from water rather than due to changes in the electrical conductivity of water, colloid-chemical state, acid-alkali balance, $\mathrm{pH}$, 
viscosity, or aggregate stability of a water-dispersion system. Under these conditions, the hardness of water does not change, but extracted particles acquire other modifications and structures and form a fine readily removable sludge in the water bulk.

Magnetic treatment does not reduce the corrosivity of water, and sometimes it increases as conditions for development of under-sludge corrosion appear. The effect of magnetic field is manifested only at the initial stage of operation, and then magnetized water retains its properties for less than a day. Therefore, flow turbulization and magnetic treatment are recommended for natural water with a total hardness less than $10 \mathrm{mg}$-equiv./L and alkalinity less than $6 \mathrm{mg}$-equiv./L in order to avoid sedimentation of scale-forming particles [44-47].

\subsubsection{Ultrasonic treatment}

Ultrasound treatment is aimed at a continuous disruption of the kinetics of crystallization in a wall layer due to the effect of ultrasonic waves on the heating surface, where phenomena caused by vibration of metal surface and scale occur. In this case, the bond strength decreases both within the scale and between the scale that has already formed and the metal. On the other hand, ultrasound can facilitate the aggregation of highly dispersed calcium carbonate species and help crush the particles that formed, which ultimately leads to the formation of sludge. Observations over many years revealed that the previously formed scale peeled off under ultrasonic treatment and sludge became more finely dispersed [48, 49].

\subsubsection{Treatment with direct electric current}

Water treatment with direct current involves passing water through a system of flat electrodes (anodes and cathodes) fed by an external voltage source. The mechanical, chemical, and electrochemical processes that occur in the system lead to the movement of solid calcium carbonate and magnesium hydroxide particles from the water flow to the cathode surfaces, where these salts are precipitated and subsequently removed by mechanical cleaning [50].

\subsection{Chemical methods for scale removal}

The chemical methods for scale removal with possible simultaneous inhibition in various technological flows are usually implemented by mixing a chemical reagent with the process flow. This ensures the treatment of almost inaccessible surfaces.

The chemical cleaning methods with application of complexing compounds and corrosion inhibitors have a number of significant advantages over the cleaning methods described above and are therefore used extensively.

The use of complexing agents allows insoluble deposits to be converted, completely or partially, into salts or complexes well soluble in water.

Inhibited solutions of hydrochloric acid are widely used to dissolve carbonate deposits. In [51, 52], the authors suggested equipment and methods for the conversion of insoluble 
carbonate-type scale into water-soluble salts by substituting the anionic part of the deposit with the solvent anion. Hydrochloric acid at various concentrations is used as such a solvent.

When added to a solution, chrysotile serves as a soft abrasive and creates a protective $\mathrm{FeSiO}_{3}$ film, which significantly inhibits the formation of new scale.

In addition to hydrochloric acid, which is ineffective for dissolving deposits with a high content of iron oxides, silicates, and phosphates, also sulfuric, nitric, sulfamic acids and formulations based on them are used as solvents [53-55].

Methods employing Trilon B (disodium dihydrogen ethylenediaminetetraacetate) for cleaning from oxide deposits by conversion of the cation from an insoluble scale to a stable soluble complex were reported in [56]. All washing methods using complexing organic acids, for example, ascorbic or citric acids, are based on the same principle.

The efficient modes of applying EDTA and etidronic acid for dissolving iron oxide and salt deposits were studied [57]. In addition to hydrochloric acid, it is suggested that methyliminodimethylphosphonic and nitrilotris(methylenephosphonic) acids can be used to remove high-temperature deposits containing significant amounts of iron, copper, and silicon oxides. Along with effective dissolution of deposits, the application of organoelement acids additionally solves the problem of waste disposal in the course of washing [58].

Methods for the conversion of deposits into a water-insoluble compound that can dissolve in other chemical reagents are also described. For example, sulfate scale deposits are first treated with trisodium phosphate to convert calcium sulfate into calcium phosphate, which is then dissolved in a hydrochloric acid solution [59].

Scale deposits consisting of copper corrosion products, magnesium hydroxide, calcium and magnesium carbonates, and calcium sulfate are removed in two stages: copper compounds are first dissolved by treatment with a ammonium carbonate solution at a concentration no higher than $100 \mathrm{~g} / \mathrm{L}$ at a temperature not higher than $50^{\circ} \mathrm{C}$; the remaining scale is dissolved in a 3-5\% hydrochloric acid solution [60].

A successful experience of cleaning heat exchangers with a carbon dioxide solution was reported [61]. This method involves dissolving the acid-forming gas in water by watergas injection, buildup of excess pressure in the equipment to be cleaned, and pressure relief. In this case, the deposits are destroyed by chemical and mechanical (due to cavitation erosion) effects.

A similar method was suggested to remove carbonate deposits from geothermal equipment. In [62], it was suggested to clean heat-power equipment by exposure to a trilon B solution followed by passivation of the heating surface by injecting oxygen into the boiler water until the complexing compound is removed completely. In this case, the cleaning time is reduced and a corrosion-resistant film is formed on the metal surface.

In [63], the results of a study on the removal of scale deposits by using an anolyte solution prepared by electrolysis of a sodium chloride brine are reported. The anolyte solution is an efficient oxidizer that destroys hydrosulphuric compounds and removes biofilms from metal surfaces. 
According to [64], a formulation based on sodium tripolyphosphate and a nitrogencontaining compound (ethanolamine borate) is recommended as a water-soluble inhibitor, which makes it possible to increase the efficiency of corrosion prevention and reduce the intensity of salt deposition; it also protects heat exchange equipment made of ferrous metals from corrosion and mechanical disintegration.

It was found that a combination of TPP with ethanolamine borate in an (80.090.0):(10.0-20.0) wt.\% ratio provides a synergistic effect of amplifying the washing, protective, and water-displacing properties of the inhibitor.

Hydrophobically modified silicon-containing polyamines comprising two types of structural repeating units are suggested for treating alumosilicate deposits in hard-to-clean industrial production lines [65]. The application of such formulations for industrial production lines results in a decrease in scale formation and removal of existing scale deposits.

A method of biochemical removal of scale is also known. According to the authors of the method, it is not corrosive to metals and safe for the environment.

The selection of cleaning method, reagents, and cleaning mode should be based on a chemical analysis of the scale deposits. Thermodynamic analysis of equilibrium processes in aqueous media is used for solving a wide range of practical problems. The kinetics and mechanism of calcite dissolution were studied with a focus on the effect of solution $\mathrm{pH}$ in order to identify environmentally-friendly modes for removal of carbonate deposits $[66,67]$.

\section{Scaling inhibition}

Recently, there have been significant changes in the operational practice of thermotechnical equipment, which affected the technologies designed for cleaning the heat exchange surfaces of equipment. At the same time, the requirements for the protection of the environment from hazardous emissions from heat power plants exceeding the maximum permissible emission limits increased.

The following requirements should be adhered to when scaling inhibitors are selected:

$\checkmark$ the thermal stability of an inhibitor must be no worse than the maximal design temperature of the working environment of a thermal power plant;

$\checkmark$ inhibitors must provide the required technological effect, i.e., the minimum rate of scale formation and/or corrosion;

$\checkmark$ the inhibitor dose loaded to the heating system and feeding water of open heat supply systems and hot water supply systems must meet the sanitary requirements and water chemistry specifications in compliance with regulatory documentation;

$\checkmark$ the inhibitor must be produced on industrial scale according to approved technical specifications.

Scale inhibitors should be selected depending on the kind of the desired process effect and intended processing conditions (correction mode - with preservation of the existing 
water treatment scheme; stabilization mode - with rejection of the entire existing water treatment scheme or its part).

\subsection{Application of phosphorus-containing complexons}

The use of phosphonates as salt deposition inhibitors (antiscaling agents) in heat supply systems provides the possibility to abandon conventional water treatment with ion-exchange filters, which in turn leads to a significant reduction in the consumption of fresh water (since water consumption for auxiliary needs of softening and desalination plants ranges from 20 to $50 \%$ of the water passed through the filters), and to the cancellation of waste water disposal. Where phosphonates are employed, heat-producing equipment can operate in a scale-free mode using water of various chemical compositions (even if the carbonate index is significantly higher than the standard value). Currently, heat supply systems use antiscale agents such as HEDP, IOMS, Amanat reagents, and PAF-13. These reagents are made in Russia and authorized for use in heat supply systems.

The effect of these inhibitors is explained by their adsorption on the surface of crystal nucleation sites, which results in the cessation of crystal growth. The complexation factor is also crucial in inhibition. The most significant effects are shown by reagents that combine surfactant and complexing properties.

The adsorption of complexons on a solid phase usually does not exceed $0.2 \mathrm{mg} / \mathrm{g}$ and is described by the Langmuir isotherm.

Since a supersaturated solution containing microsized nuclei of a solid phase is a thermodynamically unstable system, the adsorption of complexons promotes a shift in equilibrium according to the Le Chatelier principle towards the dissolution of crystal nucleation sites. As a result, the complexon is released for reactions with the new density fluctuations (nucleating sites). This is the reason for the efficiency of the action of substoichiometric amounts of reagents. A phenomenon of preventing scale deposition in supersaturated solutions of inorganic salts by adding a substoichiometric amount (microdose) of an inhibitor is commonly referred to as a threshold effect.

It should be noted that the efficiency of phosphonates (with concentrations expressed in ppm) is 5-10 times higher than that of inorganic phosphates [68, 69].

Phosphates have proven to be very efficient in preventing the scaling by such poorly soluble compounds as calcium carbonate and calcium sulfate [70]. The intensity of the effect depends on the nature of the salt and inhibitor. For example, OEDP is efficient against calcium carbonate, comparatively inefficient for calcium sulfate, but is one of the most efficient inhibitors of calcium phosphate precipitation.

It is important to emphasize that insufficient amounts of phosphonates cannot slow down crystallization, and deposits are formed in a system. With an increase in the relative inhibitor content, a substoichiometric inhibition region is observed. However, a "heterogeneity" region is formed again as the phosphonate concentration continues to increase. This region has been studied least thoroughly. Finally, when the inhibitor $/ \mathrm{Ca}^{2+}=1$ 
ratio is exceeded, the system passes into the region of molecular (true) solutions due to stoichiometric interaction of $\mathrm{Ca}^{2+}$ with organophosphonate (sequestration, masking reactions). As a result, it is impossible to determine $\mathrm{Ca}^{2+}$ in a solution by conventional titration.

It should be noted that carboxyl-containing complexons, Trilon B in particular, can also serve as masking reagents. However, the mechanism of their action involves water softening by complexation with calcium ions, which prevents the formation of calcium phosphate or carbonate scale deposits. Unlike phosphorus-containing ligands, the interaction of carboxylcontaining complexons with hardness salts assumes a substoichiometric ratio of the reagents involved in the process.

Inhibitors based on complexons comprising phosphonic groups can, at a substoichiometric ratio (i.e., 100-1000 less than the stoichiometric ratio), prevent the growth of crystallites of poorly soluble alkaline-earth metal salts.

A unique ability of phosphonic compounds to inhibit the crystallization of calcium carbonate is determined by the proximity of the parameters of the $\mathrm{CaCO}_{3}$ crystal lattice and the phosphonate ion, which has the shape of a distorted tetrahedron with a triad axis of symmetry [71].

Calcium carbonate is more inclined to form scale compared to other poorly soluble compounds. This property is caused by the strongly pronounced crystalline polymorphism of $\mathrm{CaCO}_{3}$ that forms crystals with different crystal lattices (more than 30 types), and accordingly, with different properties. Calcium carbonate is released from natural water in the form of calcite [72]. Most often, calcite crystals with scalenohedral and trigonal shapes are formed in solid deposits. In aqueous solutions, calcium carbonate crystals have acicular, laminar, star-like, and other shapes.

In the presence of phosphonate ion, $\mathrm{CaCO}_{3}$ crystallizes either as fine needle-shaped aragonite crystals that cannot form densely-packed firm deposits, or in the form of particles without any organized crystal structure.

In calcite, calcium is hexa-coordinated. The calcium coordination number in the aragonite modification increases to 9 . The increase in the calcium coordination number from 6 to 9 leads to an increase in the distance between cations and anions in a $\mathrm{CaCO}_{3}$ molecule by $4.3 \%$ on average. As a result, the energy of the crystal lattice of the deposit crystals decreases, which is manifested as a reduction in the scale strength on treatment of water with phosphonic compounds. Moreover, needle-like crystals begin to grow in the scale deposits resulting from the recrystallization of calcite into aragonite. These crystals destroy the solid deposits formed previously by the force of their growth, i.e., a surface self-cleaning process takes place, which can be considered as another phenomenon of the complexon waterchemistry mode.

Zinc complexes of phosphonic acids, for example, [1-hydroxyethylidenediphosphonate(4-) zinc disodium salt], were found to be efficient and simultaneously nontoxic corrosion inhibitors $[73,74]$. 
The widespread use of phosphonic compounds in heat power engineering is determined by the substoichiometric effect in the scale inhibition, in some cases combined with a simultaneous ability to inhibit corrosion, as well as nontoxicity.

The Scientific and Technical Council of RJSC "UES of Russia" established certain restrictions on the use of phosphonic compounds:

- the water temperature at the outlet of a water heating unit must be no higher than $110^{\circ} \mathrm{C}$;

- the water temperature at the outlet of a boiler must be no higher than $130^{\circ} \mathrm{C}$;

- the carbonate index $I_{\mathrm{c}}$ of water in the heating system must be no higher than 8 (mgequiv./kg $)^{2}$;

- the $\mathrm{pH}$ value of water in the heating system must be no higher than 8.5.

Good industrial experience with these inhibitors applied for the treatment of water with a carbonate index up to $24(\mathrm{mg}-\mathrm{eq} / \mathrm{kg})^{2}$ is available. It can be attributed to the effect of various organic compounds dissolved in water determined as permanganate oxidizability.

The results of accelerated corrosion tests of carbon steel A192 and C1015, which were treated with polyphosphates and employed as heat exchanger materials in ammonia plants, were reported [75]. It was found that carbon steel A192 had a lower corrosion rate than carbon steel C1015. This fact was attributed to a higher chromium content in carbon steel A192 than in the other steel. In this case, polyphosphate reduced the corrosion rate by up to $40 \%$ at a concentration of $150 \mathrm{ppm}$ at $32^{\circ} \mathrm{C}$. It was also found that the efficiency of polyphosphate increased with concentration and decreased with temperature.

Individual phosphonic compounds are mainly inhibitors of calcium carbonate scaling, but they do not inhibit the deposition of corrosion product.

Iron-containing compounds in feed water exist in ionic or molecular states: $\mathrm{Fe}^{2+}$, $\mathrm{Fe}(\mathrm{OH})^{+}, \mathrm{Fe}(\mathrm{OH})_{2}, \mathrm{Fe}^{3+}, \mathrm{Fe}(\mathrm{OH})^{2+}, \mathrm{Fe}(\mathrm{OH})_{3}$, etc. When the temperature of the medium rises, these compounds quickly pass through the colloidal dispersion stage; they are dehydrated and turn into coarsely dispersed iron oxides such as $\mathrm{FeO}, \mathrm{Fe}_{3} \mathrm{O}_{4}, \mathrm{Fe}_{2} \mathrm{O}_{3}$.

It has been shown that iron-containing particles can have a zeta potential up to $100 \mathrm{mV}$ and carry both positive and negative charges. When a surfactant is introduced into the initial water, the zeta potential shifts to negative values, which helps stabilize iron-containing compounds in the molecular or colloidal-dispersion state. Moreover, many surfactants are known as crystal growth regulators. Therefore, the practical applications of phosphonates for inhibiting scale deposits in hard (very hard) water can be expanded by creating formulations based on phosphonates combined with surfactants, such as complexing agents, crystal growth regulators, and/or dispersing agents [76, 77].

The general requirements for surfactants in a formulation are as follows:

- high thermal stability;

- nontoxicity; 
- environmental safety;

- strengthening the protective effects of complexons and complexonates (synergistic effect);

- corrosion inhibition.

\subsection{Methodological aspects of using phosphonates}

Despite their high efficiency, the use of phosphonates often leads to undesirable consequences, for example, plugging heat exchanger tubes of system water heaters and boilers with calcium and magnesium carbonates. This results from the lack of control over the stabilization water treatment during the implementation period and from ignoring the thermal characteristics of an object.

One of the essential conditions of successful application of scale inhibitors for heat exchanger equipment is the adequate selection of an efficient phosphonate compound for a specific object exploited under certain technological conditions, as well as its accurate dosage.

An example of an incorrect technological solution is the use of phosphonates at elevated temperatures and low circulating water rates.

The use of phosphonates as scale inhibitors has some restrictions:

1. Regarding water composition:

$\checkmark$ alkalinity $\leq 7$ mg-equiv./l;

$\checkmark \mathrm{pH}$ no higher than 8.5 ,

$\checkmark$ total $\mathrm{Fe} \leq 0.5 \mathrm{mg} / \mathrm{l}$.

If the water composition does not meet these requirements, it is possible to use a combined water treatment method, which combines inhibition with acidification or iron removal;

2. Regarding the thermal conditions:

$\checkmark$ in the case of water boilers, the temperature of outlet water should be $\leq 110^{\circ} \mathrm{C}$;

$\checkmark$ in the case of heating boilers, the temperature of outlet water should be $\leq 130^{\circ} \mathrm{C}$.

It should be noted that scaling control should be not be based on the variation in the total water hardness before and after a boiler but on the chemical control of the phosphonate content. If the water hardness after the boiler decreases by more than $0.2 \mathrm{mg}$-equiv./l, the working concentration of the inhibitor first increases and then drops down again to the recommended values. Incorrect scaling control would cause the heat exchanger to work in a wavelike mode: on the one hand, intense scaling would occur if the inhibitor amount in water is too low, and on the other hand, an increase in the phosphonate concentration would lead to the removal of calcium scale deposits. This mode is dangerous since scale deposits are formed not on all boiler surfaces but primarily on heat-stressed surfaces that are by an order 
of magnitude smaller than the entire boiler surface area. Therefore, the rate of scaling on these areas is by an order of magnitude higher than that on the rest of the boiler elements.

Therefore, in the case of small delays in changing the inhibitor dosage schedule, overheating of the metal of boiler pipes may occur due to the scale formed, which in turn may cause its burnout.

Scaling prevention by inhibition with phosphonates is not used if slow water circulation, a thin water layer, or a dead water zone exist in the system. In other cases, the use of phosphonates as scale inhibitors in closed cooling systems allows water circulation cooling systems to be operated without scale formation, with reduced consumption of feed water and a smaller waste water amount, thereby making it possible to migrate to zero-waste water circulation systems.

Thus, it is recommended first to remove the scale existing in a boiler in order to prevent the disruption of water circulation in it.

\section{Modification of heat exchange surfaces}

It is well known that hydrophobization is one of the methods for controlling the surface properties of materials [78-81].

The water repellent capability is of great importance in many areas, such as corrosion protection, self-cleaning, fouling protection, oil separation from water, frost protection, energy conversion, drug release, decreasing the liquid flow resistance, anti-fouling paints for boats, antibacterial adhesion, windshields, architectural coatings, etc. [82-84].

In addition to hydrophobic materials as such, there is also a particular group of superhydrophobic coatings. Bionic superhydrophobic (SHPC) surfaces attract attention due to their extraordinary surface characteristics and potential applications. In nature, the surfaces of many plants and animals exhibit superhydrophobic properties: these are lotus and rice leaves, shark skin, gecko foot, butterfly wing, penguin feathers, etc. [85, 86].

\subsection{Modification of metal heat transfer surfaces}

A reduced surface tension or enhanced waterproofing of metals provided by superhydrophobic surfaces are efficient means for solving the problem of reducing the metal corrosion rate. However, it should be noted that an air layer remaining as a barrier between a superhydrophobic substrate and a liquid limits the contact area between a liquid and a surface [87-89], which would inevitably reduce heat transfer.

Hydrophobic surfaces can be prepared by creating a specific hierarchical rough surface or applying materials with low surface energy to the substrate. These approaches can be used either alone or in combinations [90-92].

Superhydrophobic coatings prepared by physical adsorption have poor durability due to a relatively weak physical interaction [93]. The high energies of interaction with the material are specific to the coatings obtained by chemical adsorption of hydrophobic agents. 
It should also be noted that the surface curvature is one of the governing factors; it was found that the contact angle on cylindrical and spherical surfaces exceeded that on flat surfaces, whereas the contact angle on concave surfaces (nanopores, spherical cavities) was smaller than that on a flat surface with the same chemical composition [94].

There are some examples of air-filled SHCs used to protect heat exchange equipment, but their number is limited.

The Massachusetts Institute of Technology (MIT) has developed a method for coating the surface of a condensing device with a graphene layer one atom thick. The tests in water vapors at $100^{\circ} \mathrm{C}$ revealed that this coating provided the transition from film to drop condensation and improved heat transfer up to fourfold compared to metal surfaces where condensed water formed a layer.

Despite the successful experience of using the above methods, most of them can be applied only in laboratories and on a small scale.

The non-durability of the majority of synthetic superhydrophobic surfaces prevents their wide industrial application. These surfaces tend to lose superhydrophobicity on exposure to a corrosive medium or under mechanical impact. Therefore, solving these problems is essential for expanding the application of superhydrophobic surfaces.

Speaking about creating scale-control coatings, one should note the complexity of the problem under consideration, the solution of which implies ensuring a thermodynamical stabilization of the heterogeneous surface's wetting mode, chemical resistance, high adhesion to a substrate, and abrasion resistance. It is these properties that ensure a long-term performance of a coating in operation.

Regardless of the drawbacks and difficulties in producing superhydrophobic surfaces noted above, the usage of proven techniques and superhydrophobic additives may be helpful in protecting heat exchange equipment from scaling and corrosion.

\subsection{Polymer anti-corrosion coatings for reducing scale buildup}

One of the most efficient methods for the protection and restoration of heat exchange equipment involves applying a polymer protective coating on the inner surfaces of heat exchange tubes. Lately, this method has been gaining popularity, which is due, firstly, to the successful development of polymer materials with high thermal conductivity, and, secondly, to the paint technology that allows one to apply an ultrathin coating on an undamaged tube surface, along with placing reliable polymer seals in places where through and blind-ended corrosion pits formed [95].

The efficiency of switching from metal heat conductive surfaces to metal-polymer ones produced by applying a composite polymer coating on the inner surface of a metal tube is determined by:

- a significant increase in the durability of a system of tubes with coatings due to the high chemical and abrasive resistance of polymer coatings;

- sealing of corrosion sites that can act as scaling centers; 
- the adhesion of scale to a polymer surface is significantly weaker than to the tube metal itself. This is due to the smoother coating surface (especially compared to the tube surface with corrosion pits), as well as to the lower polarity of the inert polymer surface (compared to the oxidized metal surface), and hence, the lack of conditions for the chemical bindings of scale deposits;

- the possibility of directed modification of a surface layer for giving it additional antiscaling properties.

The polymer materials intended for a coating on heat exchange surfaces of turbine condensers should have the following properties:

- the operating temperature under regular operation conditions should be within the range of 0 to $40{ }^{\circ} \mathrm{C}$ with allowable short-term heating up to $240^{\circ} \mathrm{C}$;

- the thickness of a coating should not exceed 50-60 $\mu \mathrm{m}$, which is determined by the requirements of the minimal influence on the heat exchange process, with the heat conductivity of the coating material in the range of $1-2 \mathrm{~W} / \mathrm{m} \cdot \mathrm{K}$;

- the coefficient of linear expansion should be close to that of the metal;

- the strength of adhesion to a steel should be 50-60 MPa (normal fracture method), which should remain unchanged under the operating conditions;

- the material should possess abrasive wear resistance at 3-5\% abrasive material in the water flow to resist wear by dispersed particles;

- the coating should be even and glossy, without downflows and drips;

- it should be easy to apply and inexpensive.

Most of the manufactured polymeric materials have only some of these required characteristics. Some polymers are limited by the operating temperature; others have high viscosity that makes it impossible to apply a thin polymer layer onto a metal substrate. An excessive thickness of a coating inevitably leads to an increase in thermal resistance. Polymer materials also differ significantly in thermal and chemical resistance, as well as in adhesion to various materials.

Despite all the difficulties, a wide range of polymer materials (PVC, PE, PTFE, polyurethanes, epoxy resins, etc.) are currently employed for protecting the surfaces of heat exchange equipment. However, it should be noted that most of them need modifications that involve surface hydrophobization, improving the thermal conductivity and the level of adhesion strength, thermal and chemical resistance, abrasive strength, etc.

\subsection{Methods for modifying the surfaces of metals and polymer coatings}

The use of fluorinated modifying agents is among the most actively developing fields of research [96].

In [97], a method for imparting hydrophobicity to a pipeline steel surface was described. The method involves creating a hierarchical structure on a metal surface. At the first stage, a $\mathrm{Cu}-\mathrm{Zn}$ alloy coating is electroplated. At the second stage, the sample is 
immersed in an alkaline solution to grow hierarchical $\mathrm{CuO}$ micro- and nanostructures in situ. Modification by fluoridation using a material with low surface energy is the third stage. Brass was chosen for electrodeposition on the steel surface due to its high scaling resistance.

Surface modification by fluoridation was carried out by immersing the samples into a solution of pentadecafluorooctanoic acid in ethanol. The surface morphology of the samples was controlled by varying the parameters such as the immersion time and current density during electroplating, fluoridation time, and the $\mathrm{Zn}^{2+} / \mathrm{Cu}^{2+}$ molar ratio during electroplating.

The superhydrophobic coating thus obtained demonstrated excellent self-cleaning, corrosion resistance, anti-scaling properties, and mechanical and thermal stability under specific conditions.

Fluorine-containing polymers with extremely low surface energy are often used to create hydrophobic anti-scale coatings.

Their low wear resistance is a significant drawback, but it can be improved by modifying the composition by dispersed nanoparticles. The application of such modifying additives not only increases the wear resistance but also changes the surface roughness, which in turn provides a high value of the contact angle.

Plasma electrolytic oxidation (PEO) followed by triboelectric deposition of fluoropolymers is an efficient way to impart enhanced hydrophobicity to a titanium surface (the contact angle reaches $131^{\circ}$ ) combined with enhanced chemical resistance, wear resistance, and durability. Developers recommend such coatings as anti-corrosive, anti-scale, and biologically inert protective coatings [98].

A formulation based on the F-4 fluoroplastic aqueous dispersion and epoxy amine adduct of diethylaminopropylamine (V-EP-041oligomer) is recommended for making a thin coating that provides drop condensation of vapor on condenser plates of heat exchange units. The hydrophobic coating is fabricated by cathodic electrodeposition.

Information on the possibility of controlling the surface properties by employing superhydrophobic additives in polymer coatings appears in literature.

A method for the preparation of an organic coating with superhydrophobic surface on a copper substrate was reported [99]. A rough surface with a random micro/nanostructure is created using fluorographene (FG) nanosheets with diverse sizes and shapes prepared by liquid-phase exfoliation and placed on the surface of an epoxy coating. The morphology of the coating surface ensures excellent anti-corrosion protection, a self-cleaning capability, mechanical strength, abrasion resistance, and chemical stability both in acid and alkaline aqueous solutions.

It should be noted that recently graphene and its derivatives attracted the attention of researchers working in the field of anti-corrosion protection [100]. Fluorographene is fluorinated graphene, which is a promising carbon material with exceptional chemical stability and excellent insulating properties. It can be produced by separating the thinnest flaky layers from fluorographene bulk. 
Like hydrophobic Teflon, fluorographene is water-repellent. It displays oil-resisting and self-cleaning properties. Therefore, it can be considered as a two-dimensional substitute for polytetrafluoroethylene [101].

In work [102], the mechanism of improving the protective properties of a polyvinyl butyral coating by incorporating fluorographene is described in detail.

The authors of [103] succeeded in fabricating a composite coating based on fluorinated graphene oxide from polydimethylsiloxane with a contact angle of $173.7^{\circ}$, which was close to the maximum value ever recorded. This study served as a source of new ideas for preparing surfaces with low surface energy from atomically layered materials.

An innovative method was put forward [104] for fabricating a hydrophobic surface based on a nanostructured zinc-rich coating composed of SE200 acrylic resin and additional modification of the surface of a coating obtained by air sputtering with a perfluorodecyltriethoxysilane solution. The resulting superhydrophobic surface not only displayed a static water contact angle of $153^{\circ}$ and a water sliding angle of $7^{\circ}$, but also exhibited excellent self-repair and self-cleaning ability.

Micron-sized hierarchical structures were found on the surface of a coating with a pigment volume concentration of $90 \%$. Corrosion tests revealed that the surface modification led to an increase in the corrosion resistance of the coating caused by a decrease in the contact area between the coating and electrolyte. In addition, it was found that the described coating exhibited an excellent self-repair ability.

Another way to increase the hydrophobicity of polymer coatings is to add fluoroalcohols to paint formulations. The contact angle of the coatings thus obtained increases up to a limiting value at $5 \mathrm{wt} . \%$ of fluoroalcohols. In this case, the hydrophobicity of the coatings is the higher, the higher the concentration of $\left(\mathrm{CF}_{2}-\mathrm{CF}_{2}\right)$ groups in the fluoroalcohol. Incorporation of a fluoroalcohol into the coating is accompanied by an increase in elasticity and shock resistance due to a brittleness reduction. The hardness of the coating grows and water uptake is reduced (unlike plasticization of epoxides by well-known plasticizers such as alkyl phthalates, which reduces both hardness and water uptake).

The effects of increasing the hardness and water uptake are associated with the film surface properties. The alcohols are concentrated in a subsurface layer of the coating to provide its hydrophobicity. As a result, the hardness increases and the water uptake of the coatings decreases. Similar results were obtained for alkyd, melamine-alkyd, and melamineformaldehyde coatings.

The work [105] reports the results of successful tests of an anti-scale epoxy resin based coating filled with a PVDF (Poly(vinylidene fluoride)) powder and carbon nanotubes filled with diethylenetriamine penta(methylenephosphonic acid) combined with a zinc flake powder. The composite coating exhibited unique anti-scaling properties: the deposition of $\mathrm{CaCO}_{3}$ on the coating surface decreased by $81.6 \%$. This fact was attributed to the shielding effect produced by the coating constituents, DTPMPA and $\mathrm{Zn}^{2+}$, which are released upon corrosion of $\mathrm{Zn}$ powder, and also to the strong hydrophobicity of the coating preventing water 
and oxygen molecules from penetration into the composite coating. The strong hydrophobicity was provided by incorporation of polyvinylidene fluoride into the protective coating.

Corrosion tests showed that the impedance modulus of a prepared composite coatings was about two orders higher than that of the unfilled epoxy resin coating. Moreover, the tests revealed that the coating had high adhesion strength, thermal stability, and corrosion resistance.

Bayer et al. described the technology for fabricating hydrophobic films by dispersing sub-micron polytetrafluorethylene (PTFE) particles in molten carnauba wax-alcohol emulsions followed by spraying [106]. Subsequent thermal treatment above the melting point of the wax, $T>T_{\mathrm{m}}$, provides a possibility to impart superhydrophobicity to the surface without any additional treatment with a fluorosilane. It was found that the surface attained superhydrophobic properties only after annealing at $110^{\circ} \mathrm{C}$ for $15 \mathrm{~min}$. The contact angle exceeded $160^{\circ}$. It was shown that wax melting during the annealing improved the coating durability and provided a high chemical resistance against corrosive solvents and selfcleaning properties.

Methods for controlling the hydrophobic properties of coatings based on other filmforming compounds were reported.

In [107], a method for fabricating an anticorrosion coating displaying an increased thermal and chemical resistance was described. A chlorinated polyvinylchloride resin was used as the polymer basis for this composite. Incorporation of zinc phthalocyanine provides an increase in chemical resistance against solutions of organic acids, salts, and alkalis, a decrease in internal stress, an improvement of adhesive properties, and a reduction of curing time. Enhancement of hydrophobicity is attained by incorporating nanosized particles of layered silicates.

The literature also contains some reports describing a positive experience in the application of hydrophobic lacquer coatings based on vinyl chloride/vinyl acetate copolymers that are characterized by a high adhesion to protected surfaces [108]. Non-toxic oxides of transition metals or talc were used as the filling agent in the composite, and an epoxy resin was used as the cross-linking basis. A special surface structure was created by hydrophobized Aerosil.

A new class of superhydrophobic nanocomposite coatings prepared by dispersing molybdenum disulfide with an average particle size of about $0.5 \mu \mathrm{m}$ in polyurethane polymer was described in the literature. The formulation was sprayed onto a stainless steel substrate and left to cure at $120^{\circ} \mathrm{C}$. Then, the surfaces were silanized with trichloroperfluorooctylsilane in gaseous phase. It was shown that with an increase in the content of molybdenum disulfide nanoparticles in the polyurethane matrix, the contact angle increased up to $157^{\circ}$, whereas the contact angle of the pure polyurethane coating did not exceed $87^{\circ}$. When examining the abrasion resistance of the nanocomposite coating, it was found that the superhydrophobicity remained unchanged even after a prolonged abrasion test (abrasion length $\sim 100 \mathrm{~m}$ ). Moreover, the friction coefficient of this composite remained relatively low. 
A technology for fabricating an organic coating modified with graphene nanosheets was described [109]. A siloxane-acryl resin was used as the polymer basis, and graphene nanosheets were modified using a fluorosilane. The protective coating was applied to an aluminum surface by spraying.

It was found that addition of modified graphene increased the surface conductivity $\left(\geq 2 \mu \mathrm{S} / \mathrm{cm}\right.$ ), and the contact angle achieved $152^{\circ}$ with a low sliding angle of $\sim 7^{\circ}$. The test samples showed high corrosion resistance.

The fabrication of a hydrophobic enamel is described in [110]. A hybrid silicon-epoxy resin was suggested as the polymer basis, and nanodispersed silicon oxide was recommended as a filling agent providing a special surface relief. A carbon nanofiber and a fluorosilane were added to increase the contact angle. The achieved value of the contact angle does not exceed $122^{\circ}$.

A self-cleaning paint based on E51 epoxy resin, mesoporous $\mathrm{TiO}_{2}$, mesoporous $\mathrm{ZnO}$ modified with wax, dicyandiamide, polyetheramine, BYK-163 dispersant, levelling agent BYK-353, powdered mesoporous activated carbon, tetrabutyltitanate, glycerine, and ethylene glycol was patented [111].

\subsection{Experience in application of polymer coatings}

A successful experience in mitigation of scaling by incorporation of modifying (anti-scaling) additives into polymer composite microcapsules both into a polymer anticorrosion coating as microcapsules and onto the coating surface was reported [112].

The microcapsules were made as spheres with a phosphonate modifying additive inside. The walls were made of an epoxy polymer material. Penetration of the medium into the walls of microcapsules leads to a gradual washout of the modifying additive. These microcapsules increase the corrosion resistance significantly and favor a prolonged anti-scaling effect of the modifying additives [113-115].

The tests revealed the low adhesion of the scale layer to modified polymer coatings, which results in its spontaneous exfoliation and cracking under minor external impact or upon changes in the process parameters (see Figure 8).
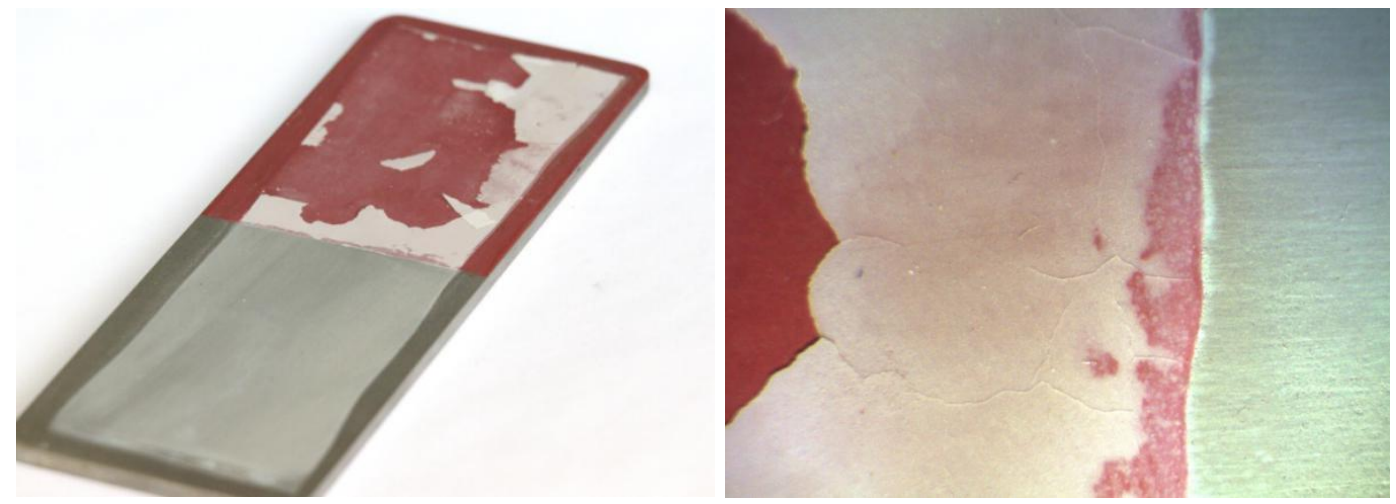

Figure 8. A picture of a sample after a scaling test. The upper part of the sample is protected by a polymer coating. 
Industrial tests verified that coatings of this type minimize scale deposits on the tube plates and inlet sections of heat exchanger tubes of a vapor condenser during long-term operation at TPP and NPP.

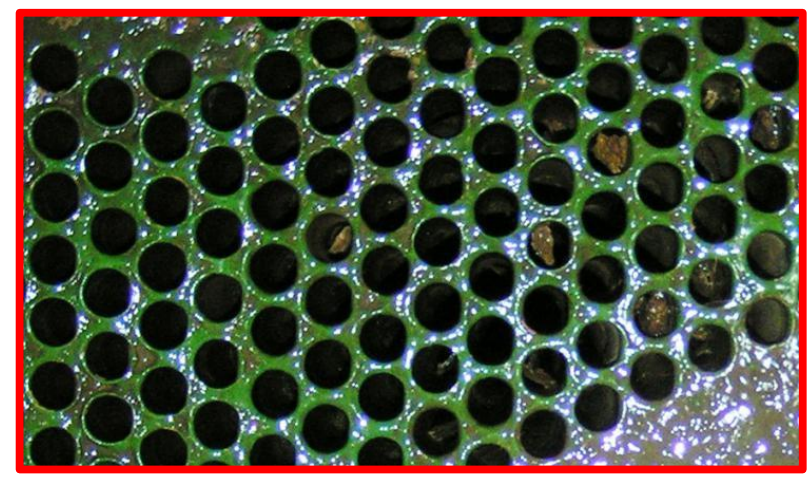

Figure 9. Scale deposits on the inlet sections of heat exchange tubes after 14 years of operation at TPP-23 of MosEnergo.

It was noted that the modified coatings exhibited high abrasion resistance in a sand pulp slurry at a sand concentration of $5 \%$ and a flow rate of $3 \mathrm{~m} / \mathrm{s}$. Therefore, they can be recommended for operation with ball cleaning systems. The wear rate is smaller than $0.5 \mu \mathrm{m}$ per $1000 \mathrm{~h}$, which helps provide the operational life of a $50 \mu \mathrm{m}$ thick coating above 10 years.

The coatings applied on heat exchange tubes at Balakovo NPP prevented scaling and fouling for 4 years. It should be noted that no visible damage, layer separation, or cracks were found in the coating, while the color and gloss of the coating surface were preserved. The anti-scaling properties of the coating made it possible to switch to periodic use of a ballbearing cleaning system [116].

Good results were obtained upon applying the modified coatings to a service heating boiler at a TPP in the Far-Eastern part of Russia. Before the coating was applied, intense formation of a layer of deposits of corrosion products of the supply water conduct occurred both on the tube plates and inside the tubes of the horizontal service water heater (SWH). After the polymer coating was applied onto some sections of the tube plates and on the internal surface of heat exchange tube packets, the protected heat exchange surfaces maintained their initial condition without any visible deposits after 7 months of operation at a temperature of $140^{\circ} \mathrm{C}$.

\section{Conclusions}

Studies and implementation of efficient, ecologically safe, and cost-effective methods for preventing scaling allow high performance of heat exchange equipment to be maintained and repair costs associated with the corrosion processes developing on the internal surfaces of heat exchange apparatus to be avoided. 


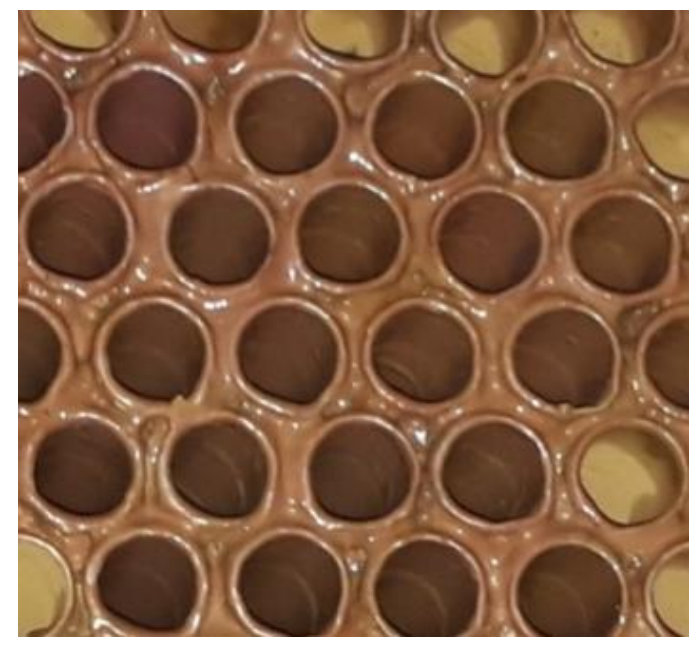

Figure 10. The appearance of the protective coating of a section of the tube plate and tube packets of the service water heater (SWH) at Khabarovsk TPP after 7 months of operation.

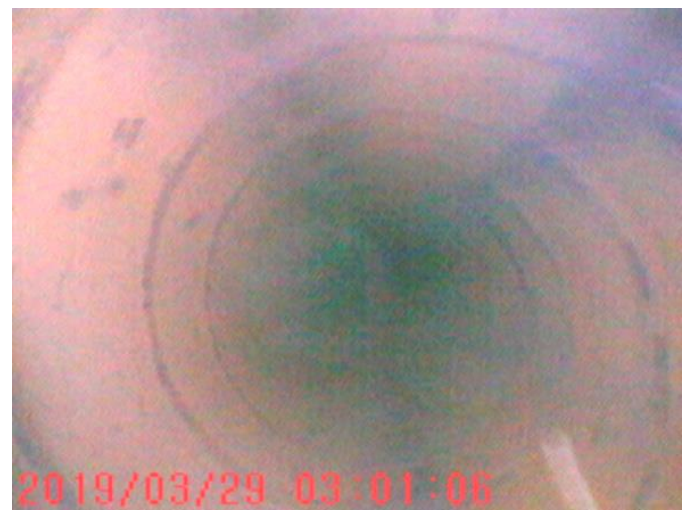

Figure 11. The appearance of the protective coating on the internal surface of the heat exchange tube with the protective coating applied along the entire length of the SWH tube after 7 months of operation.

One of the rational and environmentally responsible methods may involve applying anti-scaling or self-cleaning coatings, which also allows one to simplify the cleaning of heat exchangers and retain the heat exchange characteristics.

\section{References}

1. RD 10-165-97, Methodological guidelines for the supervision of the water-chemical regime of steam and water heating boilers, Moscow, FGUP NTTs "Promyshlennaya bezopasnost" (Industrial safety), 2004, Ser. 10, Issue 38, 23 pp. (in Russian).

2. M. Saremi, C. Dehghanian and M. Mohammadi Sabet, The effect of molybdate concentration and hydrodynamic effect on mild steel corrosion inhibition in simulated cooling water, Corros. Sci., 2006, 48, no. 6, 1404-1412. doi: $\underline{10.1016 / j . c o r s c i .2005 .06 .009}$ 
3. J.J. Maguire, Betz Handbook of Industrial Water Conditioning, Eighth ed., BETZ Labratories Inc., USA, 1980.

4. Materials of the conference of heads of turbine shops of Russian and foreign NPPs on improving the reliability and efficiency of turbine equipment, NTTs-2013, Moscow, 2013 (in Russian).

5. M.G. Mwaba, M.R. Golriz and J. Gu, A semi-empirical correlation for crystallization fouling on heat exchange surfaces, Appl. Therm. Eng., 2006, 26, no. 4, 440-447. doi: 10.1016/j.applthermaleng.2005.05.021

6. R. Sheikholeslami, Composite Fouling of Heat Transfer Equipment in Aqueous MediaA Review[J], Heat Transfer Eng., 2000, 21, no. 3, 34-42. doi: $10.1080 / 014576300270889$

7. Z. Xu, Z. Han, A. Sun and X. Yu, Numerical study of particulate fouling characteristics in a rectangular heat exchange channel, Appl. Therm. Eng., 2019, 154, pp. 657-667. doi: 10.1016/j.applthermaleng.2019.03.142

8. S.M. Alsadaie and I.M. Mujtaba, Dynamic modelling of Heat Exchanger fouling in multistage flash (MSF) desalination, Desalination, 2017, 409, 47-65. doi: 10.1016/j.desal.2017.01.020

9. Y. Lv, K. Lu and Y. Ren, Composite crystallization fouling characteristics of normal solubility salt in double-pipe heat exchanger, Int. J. Heat Mass Transfer, 2020, 156, 119883.

10. Yu.V. Balaban-Irmenin, Regularities of scale formation in hot water equipment of heat supply systems (review), Energosberezhenie $i$ vodopodgotovka, 2004, 30, no. 3, 10-16 (in Russian).

11. K. Chauhan, Removal/Dissolution of Mineral Scale Deposits, K. Chauhan, P. Sharma and Gh.S. Chauhan, Mineral Scales and Deposits, 2015, 701-720.

12. N. Andritsos and A.J. Karabelas, The influence of particulates on $\mathrm{CaCO}_{3}$ scale formation, J. Heat Transfer, 1999, 121, no. 1, 225-227. doi: $10.1115 / 1.2825951$

13. Y. Cui, S.M. Liu, K. Smith, H.Y. Hu, F.S. Tang, Y.H. Li and K.H. Yu, Stainless steel corrosion scale formed in reclaimed water: characteristics, model for scale growth and metal element release. J. Environ. Sci. (Beijing, China), 2016, 48, 79-91. doi: 10.1016/i.jes.2015.12.035

14. L.A. Kul'skii and P.P. Strokach, Basics of water chemistry and technology, Kiev, Naukova dumka, 1991, 568 pp. (in Russian).

15. P.A. Akol'zin, Corrosion and protection of metals in heat-power equipment, Moscow, Energoizdat, 1982, 303 pp. (in Russian).

16. A.M. Zimnyakov and R.V. Naumov, Analysis of chemical deposits in heat equipment and cleaning methods, Izvestiya PGPU im. V.G. Belinskogo, 2010, 21, no. 17, 104-108 (in Russian). 
17. P. Siozos, A. Philippidis, M. Hadjistefanou, C. Gounarakis and D. Anglos, Chemical analysis of industrial scale deposits by combined use of correlation coefficients with emission line detection of laser induced breakdown spectroscopy spectra, Spectrochim. Acta, Part B, 2013, 87, 86-91. doi: 10.1016/j.sab.2013.05.008

18. Yu.Yu.Lur'e, Handbook of analytical chemistry, Moscow, Khimiya, 1989, p. 448 (in Russian).

19. V.F. Vikhrev and M.S. Shkrob, Water treatment, Moscow, Energiya, 1973, 416 pp. (in Russian).

20. M.N. Persiyantsev, Oil recovery in complicated conditions, Moscow, Nedra, 2000, 653 pp. (in Russian).

21. K. Al-Anezi and N. Hilal, Scale formation in desalination plants: effect of carbon dioxide solubility, Desalination, 2007, 204, 385-402.

22. Z. Amjad, Kinetic and morphological study of calcium sulfate (gypsum) scale formation on heat exchanger surfaces in the presence of inhibitors, Korroz.: Mater., Zashch. (Corrosion: Materials, Protection), 2019, no. 8, 13-22 (in Russian).

23. M. Bohnet, Fouling of heat transfer surfaces, Chem. Eng. Tech. Process Intensif., 1987, 10, 113-125. doi: $10.1002 /$ ceat.270100115

24. A. Helalizadeh, H. Müller-Steinhagen and M. Jamialahmadi, Mixed salt crystallisation fouling, Chem. Eng. Process., 2000, 39, no. 1, 29-43. doi: 10.1016/S02552701(99)00073-2

25. H. Mori, M. Nakamura and S. Toyama, Crystallization fouling of $\mathrm{CaSO}_{4} \cdot 2 \mathrm{H}_{2} \mathrm{O}$ on heat transfer surfaces, J. Chem. Eng. Jpn., 1996, 29, no. 1, 166-173. doi: 10.1252/jcej.29.166

26. V.F. Kovalenko and G.Ya. Lukin, Ship-based water desalination plants, Leningrad, Sudostroenie, 1970, 301 pp. (in Russian).

27. Z. Amjad, Controlling the formation of silicate scale with non-ionic polymers: effect of water system contamination, Korroz.: Mater., Zashch. (Corrosion: Materials, Protection), 2018, no. 10, 9-17 (in Russian).

28. M.A. Sohai and A.I. Mustafa, Concentration control of silica in water chemical regime for natural circulation high pressure drum boiler unit of thermal power station, Indian J. Chem. Technol., 2007, no. 14, 195-199.

29. A. Bahadori and H.B. Vuthaluru, Prediction of silica carry-over and solubility in steam of boilers using simple correlation, Appl. Therm. Eng., 2010, 30, 250-253.

30. D. Jiang, H. Xu, H.I. Khan, Z. Zhu, B. Deng and N. Zhang, Transport of corrosion products in the steam-water cycle of supercritical power plant, Appl. Therm. Eng., 2017, 113, 1164-1169. doi: 10.1016/j.applthermaleng.2016.11.119

31. Yu.V. Balaban-Irmenin et al., Effect of the $\mathrm{pH}$ of sodium-cationized water on the damage to heating network pipelines, Teploenergetika, 1999, no. 2, 51-55 (in Russian).

32. T.Kh. Margulova, Use of complexons in heat power engineering, Moscow, Energoatomizdat, 1986, 211 pp. (in Russian). 
33. S.M. Peyghambarzadeh, A. Vatani and M. Jamialahmadi, Influences of bubble formation on different types of heat exchanger fouling, Appl. Therm. Eng., 2013, 50, no. 1, 848-856. doi: 10.1016/j.applthermaleng.2012.07.015

34. B. Bansal, X.D. Chen and H. Müller-Steinhagen, Analysis of 'classical' deposition rate law for crystallisation fouling, Chem. Eng. Tech. Process Intensif., 2008, 47, no. 8, 1201-1210. doi: 10.1016/j.cep.2007.03.016

35. S.N. Kazi, G.G. Duffy and X.D. Chen, Fouling and fouling mitigation on heated metal surfaces, Desalination, 2012, 288, 126-134. doi: 10.1016/j.desal.2011.12.022

36. A.V. Nerez'ko, N.B. Karnitskii and V.A. Chizh, Thermal physical properties and structure of deposits on the heating surfaces of power equipment, Izvestiya vysshikh uchebnykh zavedenii i energeticheskikh ob'edinenii SNG. Energetika, 2007, no. 1, 5560 (in Russian).

37. O.I. Martynova, I.Ya. Dubrovskii and I.V. Kurtova, Effect of flow hydrodynamics and thermal parameters on the deposition of impurities suspended in a water coolant on a non-heated channel wall, Moscow, MEI, 1974, Issue 200, 116-125 (in Russian).

38. M. Tang, J. Li, Z. Li, L. Fu, B. Zeng and J. Lv, Mannich base as corrosion inhibitors for $\mathrm{N} 80$ steel in a $\mathrm{CO}_{2}$ saturated solution containing $3 \mathrm{wt} \% \mathrm{NaCl}$, Materials, 2019, 12, no. 3, 449. doi: $\underline{10.3390 / \mathrm{ma1} 2030449}$

39. H.H. Zhang, X. Pang, Z. Meng, L. Chao, W. Liang and K. Gao, The behavior of precorrosion effect on the performance of imidazoline-based inhibitor in $3 \mathrm{wt} . \% \mathrm{NaCl}$ solution saturated with $\mathrm{CO}_{2}$, Appl. Surf. Sci., 2015, 356, 63-72. doi: 10.1016/j.apsusc. 2015.08 .003

40. R. Steinhagen, H. Muller-Steinhagen and K. Maani, Problems and costs due to heat exchanger fouling in New Zealand industries, Heat Transfer Eng., 1993, 14, no. 1, 1930. doi: $10.1080 / 01457639308939791$

41. A.B. Garrett-Price, S.A. Smith, R.L. Watts, J.G. Knudsen, W.J. Marner and J.W. Suitor, Overview of fouling, in: Fouling of Heat Exchangers, Characteristics, Costs, Prevention, Control and Removal, Noyes Publications, Park Ridge, NJ, 1985, pp. 9-19.

42. A.P. Pogrebnyak and V.L. Kokorev, RF Patent no. 2504724, F28G 7/00 (2006.01), Device for impulse cleaning of the heating surfaces of fire-tube and gas-tube boilers, claim no. 2012122001/06, claimed 28.05.2012, published 20.01.2014, Bull. Izobret. no. 2, 6 pp. (in Russian).

43. V.I. Kurets et al., RF Patent no. 22049302, F28G 5/00, Method for cleaning heat exchanger tubes from scale and device for its implementation, claim no. 5048570-12, claimed 07.04.1992, published 27.11.1995 (in Russian).

44. V.F. Ochkov, Magnetic water treatment: history and current situation, Energy saving and water treatment, 2006. no. 2 (in Russian).

45. V.V. Bannikov, Electromagnetic water treatment, Ekologiya proizvodstva, no. 4, 2004, 25-32 (in Russian). 
46. Ya.M. Shchelokov, About magnetic water treatment, Novosti teplosnabzheniya, 2002, 24, no. 8, 41-42 (in Russian).

47. M.A. Salman, M. Safar and G. Al-Nuwaibit, The Effect of Magnetic Treatment on Retarding Scaling Deposition, Online J. Sci. Technol., 2015, 5, Issue 3.

48. A.V. Nevedrov et al., Protection of heating equipment from scale by treating water with physical fields, Vestnik Kuzbasskogo gosudarstvennogo tekhnicheskogo universiteta, 2003, 32, no. 1, 73-76 (in Russian).

49. E.F. Tebenikhin, Reagent-free methods of water treatment in power plants, Moscow, Energiya, 1977, 312 pp. (in Russian).

50. G.V. Ushakov, Anti-scaling devices for the protection of water heating equipment from scale and issues of their industrial safety, Vestnik Kuzbasskogo gosudarstvennogo tekhnicheskogo universiteta, 2009, no. 3, 112-116 (in Russian).

51. V.S. Mal'kov et al., RF Patent no. 2482223, C23G 1/06 C23G 14/06 (2000.01), Means for removal of rust, scale and other mineral deposits based on glyoxal and its derivatives, no. 2011144982/02, claimed 19.08.2011, published 20.05.2013, Bull. Izobret. no. 14, 6 pp. (in Russian).

52. O.A. Kolotygin and E.V. Lifanov, RF Patent no. 2404397, F28G 9/00, B08B 3/08 (2006.01), Device for cleaning heat exchange equipment from deposits and scale (options), no. 2009128536/12, claimed 23.04.2009, published 20.11.2010, Bull. Izobret. 32, 16 pp. (in Russian).

53. V.V. Bovt and A.I. Mikov, RF Patent no. 2497941, C11D 7/32, C09K 8/52, C09K 8/528 (2006.01), Formulation based on carbamide nitrate and a method for producing a formulation based on carbamide nitrate, no. 201204930/04, claimed 13.02.2012, published 10.11.2013, Bull. Izobret. 31, 8 pp. (in Russian).

54. P.N. Kudinov, RF Patent no. 2299275 F23G 1/02 (2006.01), A method to obtain a formulation for cleaning surfaces from deposits of metal salts, oxides and hydroxides (options), no. 2005122194/02, claimed 13.07.2005, published 20.05.2007, Bull. Izobret. no. 14, 7 pp. (in Russian).

55. Ya.G. Avdeev and Yu.I. Kuznetsov, Inhibitory protection of steels from hightemperature corrosion in acid solutions. A review. Part 1, Int. J. Corros. Scale Inhib., 2020, 9, no. 2, 394-426. doi: 10.17675/2305-6894-2020-9-2-2

56. A.G. Aptekman et al., RF Patent no. 2172301, C02F 5/08, F28G 9/00 (2000.01), A washing formulation for scale removal, no. 2000110279/12, claimed 25.04.2000, published 20.08.2001, Bull. Izobret. 23, 9 pp. (in Russian).

57. I.G. Gorichev et al., Comparative evaluation of the effectiveness of the action of aqueous solutions of EDTA and HEDP in the dissolution of magnetite, Zhurnal neorganicheskoi khimii, 2009, 54, no. 5, 869-880 (in Russian).

58. B.N. Driker et al., RF Patent 2177458, C02F 5/14, C23F 14/02, A formulation for removal of high-temperature mineral scale deposits from heat and power equipment, no. 2000111912/12, claimed 12.05.2000, published 27.12.2001, 9 pp. (in Russian). 
59. N.A. Yankovskii et al., RF Patent no. 2150645, F28G 9/00 (2000.01), A method for cleaning steam boilers, no. 99109772/06, claimed 05.05.1999, published 10.06.2000, Bull. Izobret., no. 16, 3 pp. (in Russian).

60. O.D. Linnikov et al., RF Patent no. 2359196, F28G 9/00, C23G 1/14, C23F 1/18 (2006.01), A method for cleaning equipment from deposits with high copper content, no. 2007134131/02, claimed 12.09.2007, published 20.06.2009 Bull. Izobret., no. 17 (in Russian).

61. I.G. Fil'tsov et al., RF Patent no. 2270967, F28G 9/00 (2006.01), A method for cleaning a heat exchanger from scale, no. 2003131131/12, claimed 22.10.2003, published 27.02.2006, 8 pp. (in Russian).

62. G.Ya. Akhmedov, RF Patent no. 2528776, F28G 9/00 (2006.01), A method for cleaning heat exchange equipment, no. 2013109835/06, claimed 05.03.2013, published 20.09.2014, Bull. Izobret., no. 26, 6 pp. (in Russian).

63. Z.M. Aliev et al., A study on electrochemically synthesized anolyte for cleaning internal pipelines from scale, Vestnik Dagestanskogo gosudarstvennogo universiteta, 2014, no. 6, 148-150 (in Russian).

64. RF Patent no. $23555820 \mathrm{C} 1$.

65. RF Patent no. 2455318 C2.

66. I.V. Artamonova and I.G. Gorichev, Environmental specifics of removing carbonate deposits from heating equipment surfaces, Izvestiya MGTU MAMI, 2009, 8, no. 2, 220227 (in Russian).

67. N.G. Shagiev et al., Thermodynamic analysis of processes in water circuits of power plants during chemical purification using compositions based on complexons, Problemy energetiki, 2003, no. 11-12, 82-88 (in Russian).

68. S.G. Red'kina, Yu.I. Kuznetsov, L.V. Frolova and A.A. Chirkunov, Inhibition of corrosion of low-carbon steel in formation water by compositions based on phosphonates, Vestnik TGU, 2013, 18, no. 5, 2313-2316 (in Russian).

69. G.V. Redkina, Yu.I. Kuznetsov, N.P. Andreeva, I.A. Arkhipushkin and L.P. Kazansky, Features of zinc passivation by sodium dodecylphosphontate in a neutral aqueous solution, Corros. Sci., 2020, 168, 108554. doi: 10.1016/j.corsci.2020.108554

70. R.T. Burganov, A.R. Gil'mullina and E.A. Kovrizhnykh, Comparative studies on corrosion and scale inhibitors based on organophosphorus compounds, Korroz.: Mater., Zashch. (Corrosion: Materials, Protection), 2018, no. 5, 17-22 (in Russian).

71. R. Ketrane, B. Saidani, O. Gil, I. Leleyter and F. Baraud, Efficiency of five scale inhibitors on calcium carbonate precipitation from hard water. Effect of temperature and concentration, Desalination, 2009, 249, 1397-1404.

72. A.T. Bogorash, I.S. Gulyi, I.M. Fedotkin et al., Controlling the process of mass crystallization of synthetic needle crystals, Dokl. AN SSSR, 1975, 223, no. 4, 928-931 (in Russian). 
73. A.A. Chirkunov, D.O. Chugunov, G.V. Red'kina and Yu.I. Kuznetsov, Effect of surface modification of steel with zinc complexes of phosphonic acids on the efficiency of its passivation with organic inhibitors, Elektrokhimiya, 2019, 55, no. 2, 214-221 (in Russian).

74. Yu.I. Kuznetsov, Organic corrosion inhibitors: where are we now? Overview. Part IV1. Passivation of metals and the role of mono- and diphosphonates in it, Korroz.: Mater., Zashch. (Corrosion: Materials, Protection), 2018, no. 1, 1-17 (in Russian).

75. A. Nikitasari, Sundjono, G. Priyotomo and A. Royani, Polyphosphate performance for inhibiting corrosion of heat exchanger materials, Int. J. Corros. Scale Inhib., 2020, 9, no. 2, 745-756. doi: 10.17675/2305-6894-2020-9-2-22

76. G.Ya. Rudakova, V.E. Larchenko and N.V. Tsirul'nikova, Theory and practice of using complexons in the energy sector. Materials of the conference "Modern technologies of water treatment and protection of equipment from corrosion and scale formation", Moscow, IREA, 2003, pp. 11-19 (in Russian).

77. Yu.V. Balaban-Irmenin, G.Ya. Rudakova, V.E. Larchenko and A.M. Rubanov, On the issue of the method for choosing the brand and dose of an antiscalant for heat supply systems, Energosberezhenie i vodopodgotovka, 2005, no. 3, 5-8 (in Russian).

78. P. Zhang and F.Y. Lv, A review of the recent advances in superhydrophobic surfaces and the emerging energy-related applications, Energy, 2015, 82, 1068-1087.

79. G. Barati Darband, M. Aliofkhazraei, S. Khorsand, S. Sokhanvar and A. Kaboli, Science and engineering of superhydrophobic surfaces: review of corrosion resistance, chemical and mechanical stability, Arab. J. Chem., 2018, 123, 21-26.

80. S.S. Latthe, R.S. Sutar, V.S. Kodag, A.K. Bhosale, A.M. Kumar, K. Kumar Sadasivuni, R. Xing and S. Liu, Self - cleaning superhydrophobic coatings: potential industrial applications, Prog. Org. Coat., 2019, 128, 52-58.

81. L. Cao, A.K. Jones, V.K. Sikka, J. Wu and D. Gao, Anti-Icing superhydrophobic coatings, Langmuir, 2009, 25, 12444-12448.

82. U. Mehmood, F.A. Al-Sulaiman, B.S. Yilbas, B. Salhi, S.H.A. Ahmed and M.K. Hossain, Superhydrophobic surfaces with antireflection properties for solar applications: a critical review, Sol. Energy Mater. Sol. Cells, 2016, 157, 604-623.

83. H.J. Gwon, Y. Park, C.W. Moon, S. Nahm, S.J. Yoon, S.Y. Kim and H.W. Jang, Superhydrophobic and antireflective nanograss-coated glass for high performance solar cells, Nano Res., 2014, 7, 670-678.

84. P. Zhang amd F.Y. Lv, A review of the recent advances in superhydrophobic surfaces and the emerging energy-related applications, Energy, 2015, 82, 1068-1087.

85. X.F. Gao and L. Jiang, Biophysics: water-repellent legs of water striders, Nature, 2004, $432,36$.

86. X. Gao, X. Yan, X. Yao, L. Xu, J. Xhang, K. Zhang, B. Yang and L. Jiang, The dry-style antifrogging properties of mosquite compound eyes and artificial analogues prepared by soft lithography, Adv. Mater., 2007, 19, 2213-2217. 
87. F.Z. Zhang, L.L. Zhao, H.Y. Chen, S.L. Xu, D.G. Evans and X. Duan, Corrosion resistance of superhydrophobic layered double hydroxide films on aluminum, Angew. Chem. Int. Ed., 2008, 47, 2466-2469.

88. T. Liu, S.G. Chen, S. Cheng, J.T. Tian, X.T. Chang and Y.S. Yin, Corrosion behavior of super-hydrophobic surface on copper in seawater, Electrochim. Acta, 2007, 52, 80038007.

89. Y.S. Yin, T. Liu, S.G. Chen, T. Liu and S. Cheng, Structure stability and corrosion inhibition of super-hydrophobic film on aluminum in seawater, Appl. Surf. Sci., 2008, 255, 2978-2984.

90. G. Wang and T.Y. Zhang. Easy route to the wettability cycling of copper surface between superhydrophobicity and superhydrophilicity, ACS Appl. Mater. Interfaces, 2012, 4, no. 1, 273-279. doi: 10.1021/am2013129

91. A. Hooda, M.S. Goyat, J.K. Pandey, A. Kumar and R. Gupta, A review on fundamentals, constraints and fabrication techniques of superhydrophobic coatings, Prog. Org. Coat., 2020, 142, 105557.

92. J. Long, M. Zhong, P. Fan, D. Gong and H. Zhang, Wettability conversion of ultrafast laser structured copper surface, J. Laser Appl., 2015, 27, S29107. doi: $\underline{10.2351 / 1.4906477}$

93. V. Mortazavi and M. Khonsari, On the degradation of superhydrophobic surfaces: a review, Wear, 2017, 372, 145-157.

94. L.B. Boinovich and A.M. Emelyanenko, The prediction of wettability of curved surfaces on the basis of the isotherms of the disjoining pressure, Colloids Surf., A, 2011, 383, no. $1-3,10-16$.

95. V.A. Golovin, A.N. Kaz'min and A.M. Nemytova, Experience gained from using protective coating of cooling tubes in the condensers at the Leningrad and the Smolensk nuclear power plants, Therm. Eng., 2012, 59, 119-124. doi: 10.1134/S0040601512020048

96. M.Yu.Kvasnikov, Fluorine-containing paint and varnish formulations and coatings based thereon, Khimicheskaya promyshlennost' segodnya, 2008, no. 7, 22-26 (in Russian).

97. H. Li, S. Yu, X. Han and Y.Zhao, A stable hierarchical superhydrophobic coating on pipeline steel surface with self-cleaning, anticorrosion, and anti-scaling properties, Colloids Surf., A, 2016, 503, 43-52.

98. S.V. Gnedenkov, S.L. Sinebryukhov, D.V. Mashtalyar, V.M. Buznik, A.M. Emel'yanenko and L.B. Boinovich, Hydrophobic properties of composite fluoropolymer coatings on titanium, Fizikokhimiya poverkhnosti i zashchita materialov, 2011, 47, no. 1, 86-94 (in Russian).

99. Z. Yang, L. Wang, W. Sun, S. Li, T. Zhu, W. Liu and G. Liu, Superhydrophobic epoxy coating modified by fluorographene used for anti-corrosion and self-cleaning, Appl. Surf. Sci., 2017, 401, 146-155. 
100. W. Sun, L.D. Wang, T.T. Wu, M. Wang, Z.Q. Yang, Y.Q. Pan and G.C. Liu, Inhibiting the corrosion-promotion activity of graphene, Chem. Mater., 2015, 27, 2367-2373.

101. M. Zhang, Y.C. Ma, Y.Y.Zhu, J.F. Che and Y.H. Xiao, Two-dimensional transparent hydrophobic coating based on liquid-phase exfoliated graphene fluoride, Carbon, 2013, 63, $149-156$.

102. Z.Q. Yang, W. Sun, L.D. Wang, S.J. Li, T.Z. Zhu and G.C. Liu, Liquid-phase exfoliated fluorographene as a two dimensional coating filler for enhanced corrosion protection performance, Corros. Sci., 2016, 103, 312-318.

103. T. Bharathidasan, T.N. Narayanan, S. Sathyanaryanan and S.S. Sreejakumari, Above $170^{\circ}$ water contact angle and oleophobicity of fluorinated graphene oxide based transparent polymeric films, Carbon, 2015, 84, 207-213.

104. L. Xu, F. Liu, M. Liu, Z. Wang, Z. Qian, W. Ke, E.-H. Han, G. Jie, J. Wang and L. Zhu, Fabrication of repairable superhydrophobic surface and improved anticorrosion performance based on zinc-rich coating, Prog. Org. Coat., 2019, 137, 105335. doi: 10.1016/j.porgcoat.2019.105335

105. X. Chen, H. Wang, C. Wang, W. Zhang, C. Lv and Y. Zhu, A novel antiscaling and anticorrosive polymer-based functional coating, J. Taiwan Inst. Chem. Eng., 2019, 97, 397405.

106. I.S. Bayer, D. Fragouli, P.J. Martorana, L. Martiradonna, R. Cingolani and A. Athanassiou, Solvent resistant superhydrophobic films from self-emulsifying carnauba wax-alcohol emulsions, Soft Matter, 2011, 7, no. 18, 7939-7943. doi: 10.1039/C1SM05710C

107. RF Patent no. 2067106.

108. RF Patent no. 2650135.

109. P.C. Uzoma， F. Liu， L. Xu， Z. Zhang， E.-H. Han, W. Ke and I.O. Arukalam, Superhydrophobicity, conductivity and anticorrosion of robust siloxane-acrylic coatings modified with graphene nanosheets. Prog. Org. Coat., 2019, 127, 239-251. doi: 10.1016/j.porgcoat.2018.11.018

110. RF Patent no. 2441045.

111. H. Ma, Self-cleaning green environment-friendly paint containing epoxy resin and its preparation method, CN 107880735 A 20180406.

112. A.B. Il'in, V.A. Shchelkov, S.A. Dobriyan, V.B. Lukin and V.A. Golovin, Polymer coatings for the protection of heat exchanger tubes of steam condensers from corrosion and scale deposits, Mezhdunarodnyi nauchno-issledovatel'skii zhurnal (International Research Journal), 2018, 71, no. 5, 69-75 (in Russian; abstract in English). doi: 10.23670/IRJ.2018.71.037

113. V.A. Golovin, A.B. Il'in, V.T. Kuznets and A.R. Vartapetyan, RF Patent no. 2358036, A method for corrosion protection of metal surfaces with inhibited polymer formulations and microcapsules with a corrosion inhibitor, registered 10.06.2009. 
114. V.A. Golovin, V.T. Kuznets, K.V. Kublitsky and A.B. Ilin, US patent 7,836,844 B2, Nov. 23, 2010, Method for protection against corrosion and scale deposit and for restoring tubes of heat-exchanging equipment and device for carrying out said method.

115. V.A.Golovin, Prevention of scaling and corrosion of heat transfer surfaces of NPP condensers, Conference of heads of turbine shops of Russian and foreign NPPs on improvement of the reliability and performance of turbine equipment, JSC "Kontsern Rosenergoatom", February 13-15, 2018 (in Russian).

116. V.A. Golovin, A.B. Il'in and A.D. Aliev, Diffusion of phosphonic scale inhibitors in epoxy matrices, Mezhdunarodnyi nauchno-issledovatel'skii zhurnal (International Research Journal), 2018, 70, no. 4, 92-96 (in Russian). 